\title{
An Atlas of a Rare Neuronal Surface Antigen in the Rat Central Nervous System
}

\author{
D. T. Stephenson and P. D. Kushner \\ ALS and Neuromuscular Research Foundation, Pacific Presbyterian Medical Center, San Francisco, California 94115
}

The mature nervous system contains functional synaptic networks composed of neuronal sets and subsets whose identity and maintenance may rely on external surface molecules specific for these neuronal subdivisions. Such molecules may reside permanently on specific neurons, serving to identify those neurons within a complex population. From a collection of monoclonal antibodies made to the Torpedo cholinergic synaptosome preparation, we have identified several antibodies that bind the surface of some, but not all, neurons of the mature rat brain (Kushner and Stephenson, 1983; Kushner, 1984). In the present study we catalog which neurons of the entire rat brain and spinal cord are immunopositive for one of these antibodies, Tor 23 . The atlas we have compiled can be used (1) on a practical level to guide affinity purifications and neuronal cell sorting, and (2) more esoterically to address whether surface antigenic sets of neurons share or define a common functional property. In the forebrain, Tor 23-positive neurons predominate as a rare cell type of the inner cortical laminae. In the midbrain, few cells stain. In the hindbrain, labeled neurons are dispersed among several nuclei. The exceptions to these observations, areas that almost exclusively contain Tor 23immunopositive neurons, are the spinal cord ventral horn, the deep cerebellar nuclei, some cerebellar-related nuclei, selected auditory nuclei, the supraoptic and paraventricular nuclei of the hypothalamus, and the CA2 pyramidal neurons of the hippocampus. The neurons that bind Tor 23 are related biochemically by virtue of that shared epitope alone. Whether they are related in a functional manner is a separate issue. Tor 23 demarks many motor-related structures, specifically, the ventral horn motor lamina, the orofacial motor nuclei 5 and 7 , the ambiguus nucleus, the deep cerebellar nuclei, the pontine reticulotegmental nucleus, the lateral reticular nucleus, the gigantocellular reticular nucleus, the red nucleus, and neurons within the motor and somatosensory cortices. The overlap of Tor $\mathbf{2 3}$ with motor structures suggests that Tor 23 is a motor system marker.

\footnotetext{
Received Sept. 22, 1987; revised Nov. 23, 1987; accepted Nov. 27, 1987.

This work was supported by grants from the ALS Association and the ALS and Neuromuscular Research Foundation. We thank Allan Basbaum and Michael Mcrzenich for helpful discussions, and Sarah Wright for helpful discussions and criticisms of the manuscript.

Correspondence should be addressed to Pinky Drosten Kushner, ALS and Neuromuscular Research Foundation, 2351 Clay Street, Rm. 416, San Francisco, CA 94115.

Copyright (C) 1988 Society for Neuroscience $0270-6474 / 88 / 083035-22 \$ 02.00 / 0$
}

The last 25 years have witnessed the elaboration of a field called "chemical neuroanatomy," a discipline whereby neuronal types are defined by the neurochemicals they contain as much as by their morphological, biophysical, or connective properties. A potential extension of this chemical neuroanatomy is the delineation of the neuronal subsets on the basis of cell surface molecules.

There is ample evidence from recent work suggesting that surface molecules demark neuronal sets and subsets in the mature brain of vertebrates (Cohen and Selvendran, 1981; Delpech et al., 1982; Garson et al., 1982; Richardson et al., 1982; Wood et al., 1982; Barnstable et al., 1983; Hockfield and McKay, 1983; Hockfield et al., 1983; Morris and Barber, 1983; Kushner, 1984; Levitt, 1984; Allen and Akeson, 1985; Levitt et al., 1986; Arimatsu et al., 1987; Trisler and Collins, 1987) and invertebrates (Zipser and McKay, 1981; Hogg et al., 1983; Patel et al., 1987). In only a few of the simpler systems - the highly stereotyped leech nervous system (Zipser, 1982; Peinado et al., 1987) and neurons of the vertebrate CNS versus PNS (Cohen and Selvendran, 1981; Vulliamy et al., 1981)-has a complete and exact description of immunopositive neurons been established. Other studies lack a full description of precisely which specific neurons are positive for the particular surface molecule. This issue is critical in order to capitalize on these surface molecules in affinity purifications and cell sorting, and to address whether neurons that share surface molecules belong to particular biochemical or functional categories. A careful delineation of the complete neuronal set positive for a particular rare surface antigenic determinant is the first requirement. An analysis of precisely which neurons are positive and which are negative in the mammalian CNS is not trivial, however, since the positive neurons often may represent only a small fraction of total neurons in a complex population.

Tor 23 is a monoclonal antibody from a large library of antibodies made to the Torpedo cholinergic synaptosome preparation (Kushner, 1984). Previous studies have shown that this antibody binds motor neurons and their processes with a broad species cross-reactivity, binding Torpedo (Buckley et al., 1983; Kushner, 1984; Kushner et al., 1987b), frog (Kushner, 1984), rat (Kushner, 1984; Stephenson et al., 1987), and human (Bjornskov et al., 1988). As verified with immunoelectron microscopy (Buckley et al., 1983; Kushner, 1984), immunoprecipitation (Buckley et al., 1983), and live cell staining (Kushner et al., 1987a), Tor 23 binds the external neuronal surface.

The present report confirms the finding of initial investigations that Tor 23 binds the perimeter of a restricted number of 

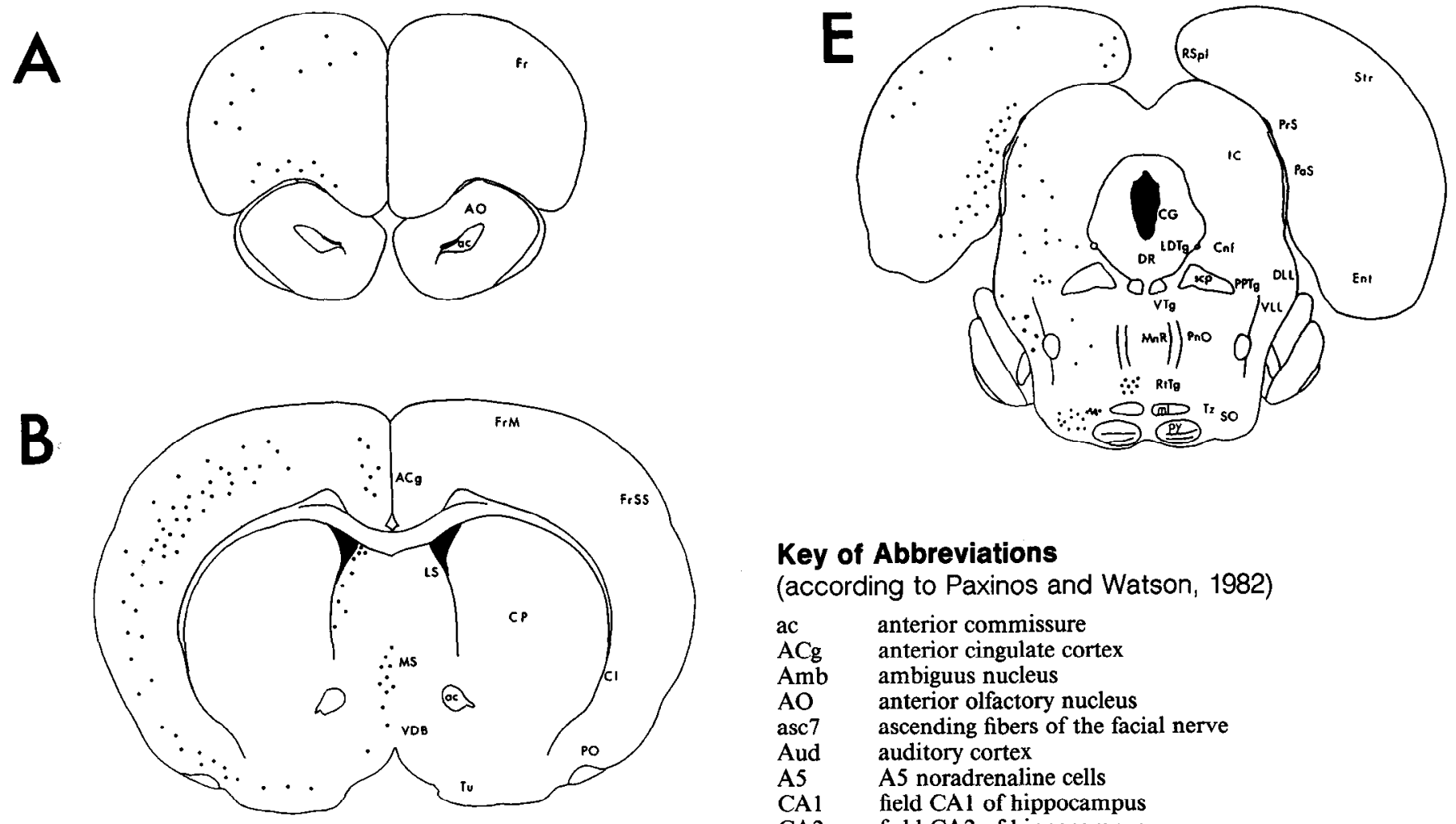

Key of Abbreviations

(according to Paxinos and Watson, 1982)

ac anterior commissure

$\mathrm{ACg}$ anterior cingulate cortex

$\mathrm{Amb}$ ambiguus nucleus

$\mathrm{AO}$ anterior olfactory nucleus

asc7 ascending fibers of the facial nerve

Aud auditory cortex

A5 A5 noradrenaline cells

CA1 field CA1 of hippocampus

CA2 field CA2 of hippocampus

CA3 field CA3 of hippocampus

CA4 field CA4 of hippocampus

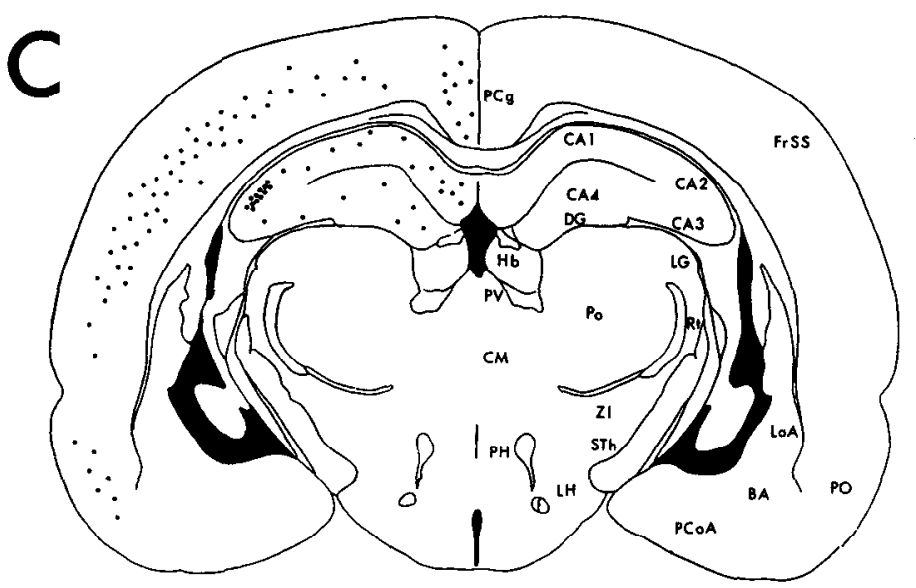

$\mathrm{CG}$ central (periaqueductal) gray

$\mathrm{Cl}$ claustrum

$\mathrm{CM}$ central medial thalamic nucleus

Cnf cuneiform nucleus

DCo dorsal cochlear nucleus

DG dentate gyrus

DLL dorsal nucleus lateral lemniscus

DR dorsal raphe nucleus

DTg dorsal tegmental nucleus

$\mathrm{ECu}$ external cuneate nucleus

Ent entorhinal cortex

EW accessory oculomotor nucleus, Edinger-Westphal

f fornix

Fr frontal cortex

FrM frontoparietal cortex, motor area

FrSS frontoparietal cortex, somatosensory area

GCo granule cell layer, cochlear nucleus

$\mathrm{Gi}$ gigantocellular reticular nucleus

$\mathrm{Hb}$ habenular nucleus

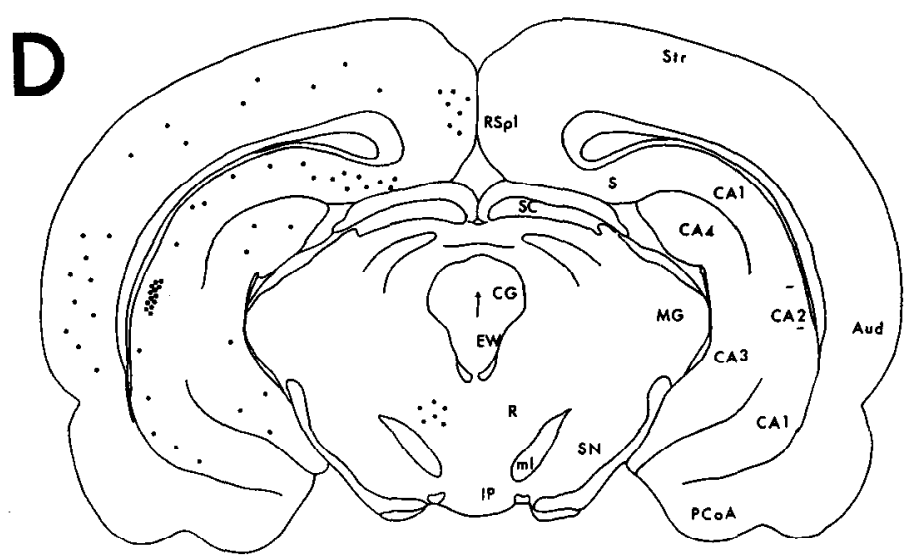

IC inferior colliculus

Int interpositus cerebellar nucleus

IO inferior olive

IP interpeduncular nucleus

$\mathrm{La}$ lateral amygdaloid nucleus

Lat lateral (dentate) cerebellar nucleus

LDTg laterodorsal tegmental nucleus

LG lateral geniculate nucleus

LH lateral hypothalamic area

LRt lateral reticular nucleus

LS lateral septal nucleus

$\mathrm{LVe} \quad$ lateral vestibular nucleus

MG medial geniculate nucleus

$\mathrm{ml}$ medial lemniscus

MnR median raphe nucleus

Mo5 motor trigeminal nucleus

MS medial septal nucleus

Figure 1. Atlas of Tor 23-positive somata in the rat CNS. For construction of the atlas, transverse levels were chosen in representative areas of the brain and spinal cord that contain relatively significant numbers of immunoreactive neurons. The number of $d o t s$ reflects the relative concentration of positive neurons in the different CNS regions. [Diagrams were reconstructed from the atlas of Paxinos and Watson (1982) and correspond to the following plates (designated as PW): $A$, PW 6; $B$, PW 14; $C$, PW 22; $D$, PW 26; $E$, PW 31; F, PW 34; G, PW 37; $H$, PW 41; $I$, PW 68.] For abbreviations, see accompanying key. 


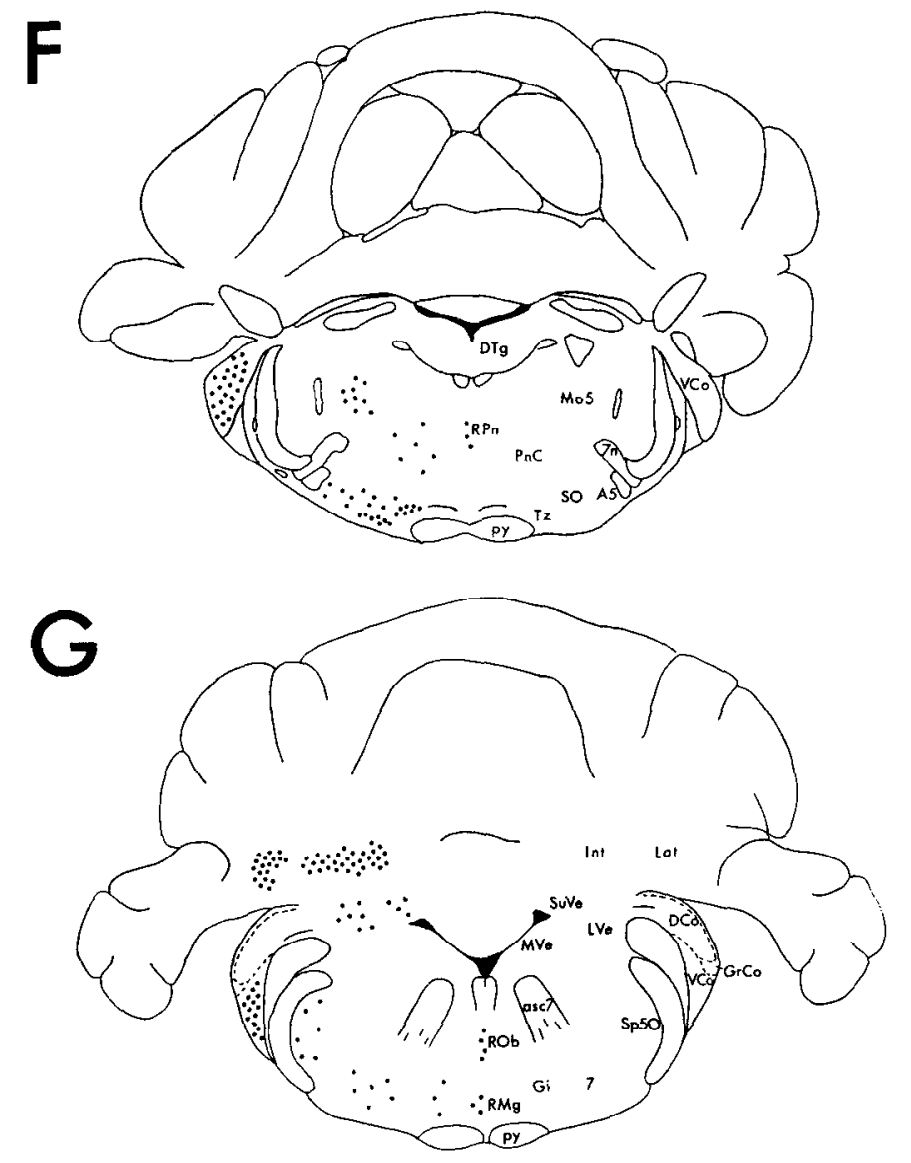

MVe medial vestibular nucleus

$\mathrm{PaS}$ parasubiculum

$\mathrm{PCg}$ posterior cingulate cortex

PCOA posterior cortical amygdaloid nucleus

PcRt parvocellular reticular nucleus

PH posterior hypothalamic nucleus

PnC pontine reticular nucleus (caudal)

$\mathrm{PnO}$ pontine reticular nucleus (oral)

Po posterior thalamic nuclear group

PO primary olfactory (piriform) cortex

PPTg pedunculopontine tegmental nucleus

PrS presubiculum

PV paraventricular thalamic nucleus

py pyramidal tract

$R$ red nucleus

$\mathrm{RMg}$ raphe magnus nucleus

$\mathrm{ROb}$ raphe obscurus nucleus

RPn raphe pontis nucleus

RSpl retrosplenial cortex

$\mathrm{Rt}$ reticular thalamic nucleus

$\mathrm{R} t \mathrm{Tg}$ reticulotegmental nucleus

$\mathrm{S}$ subiculum

SC superior colliculus

scp superior cerebellar peduncle

SN substantia nigra

SO superior olive

Sol nucleus of the solitary tract

Sp5I nucleus spinal tract trigeminal nerve (intcrpolar)

Sp5O nucleus spinal tract trigeminal nerve (oral)

STh subthalamic nucleus

Str striate cortex

SuVe superior vestibular nucleus

$\mathrm{Tz}$

trapezoid body nuclei, medial and lateral ventral cochlear nucleus

nucleus of the diagonal band, vertical limb

ventral nucleus lateral lemniscus

ventral tegmental nucleus

zona incerta

facial nucleus

facial nerve (root of facial nerve)

dorsal motor nucleus of vagus

hypoglossal nucleus

Spinal cord

$\begin{array}{ll}1 & \text { lamina I } \\ 2 & \text { lamina II } \\ 3 & \text { lamina III } \\ 4 & \text { lamina IV } \\ 5 & \text { lamina V } \\ 7 & \text { lamina VII } \\ 8 & \text { lamina VIII } \\ 9 & \text { lamina IX } \\ \mathrm{dcs} & \text { dorsal corticospinal tract } \\ \mathrm{dr} & \text { dorsal root of spinal nerve } \\ \mathrm{IML} & \text { intermediolateral cell column } \\ \mathrm{vr} & \text { ventral root of spinal nerve }\end{array}$

Figure 1. Continucd. 


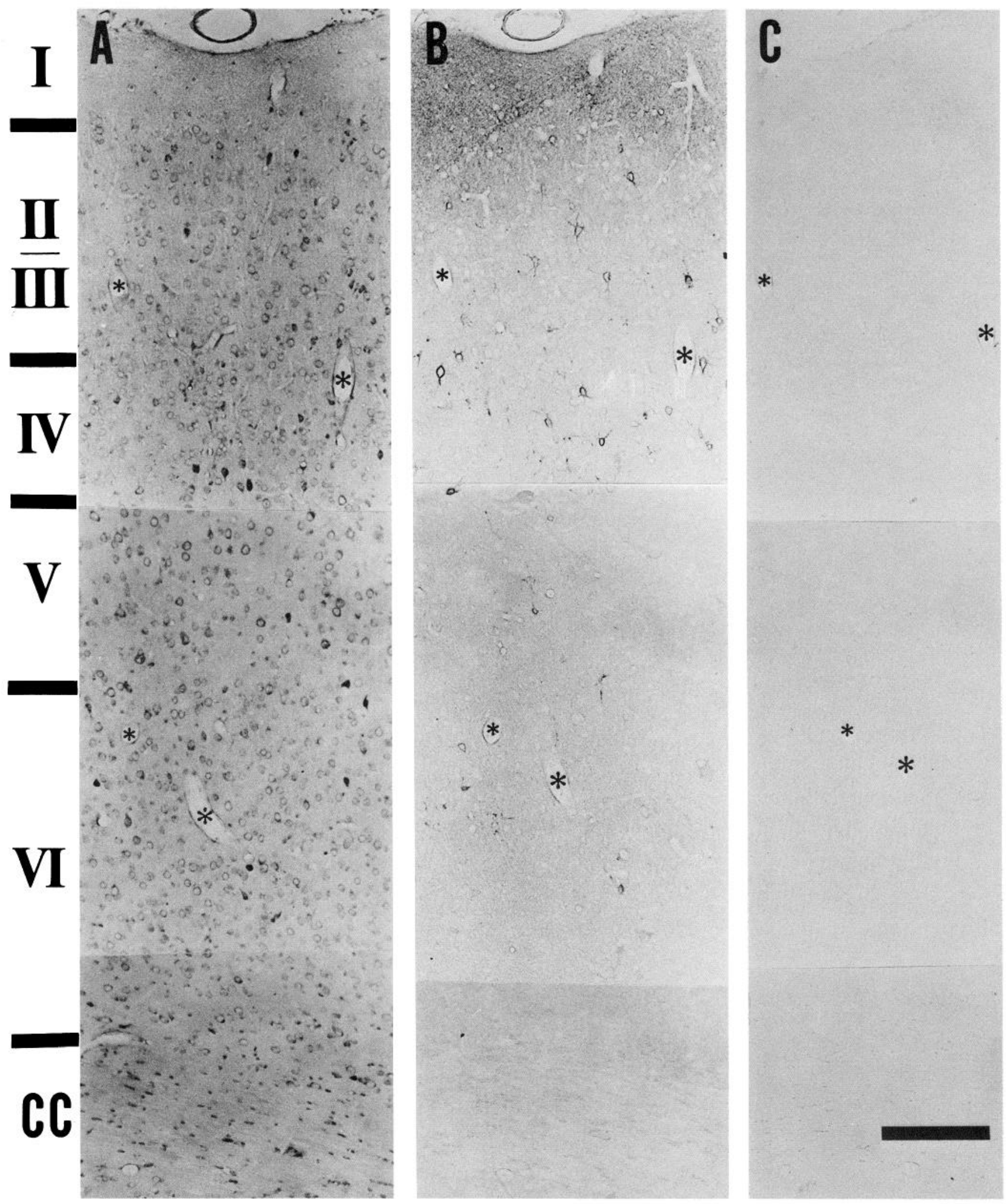

Figure 2. Tor 23 binding is localized to a subpopulation of cortical neurons primarily present in laminae II-IV. Adjacent forebrain sections were stained with cresyl violet $(A)$, Tor 23 using immunoperoxidase $(B)$, and immunoperoxidase label alone $(C)$. Photomicrographs are from somatosensory cortex. Counting cresyl violet-stained cells $(A)$ relative to Tor 23-labeled somata $(B)$ reveals that antibody-positive cells comprise $7 \%$ of the total neuronal population in this field, inclusive of all laminae. No stain is observed in the section incubated in control medium and stained with immunoperoxidase label alone $(C)$. Asterisks mark positions of orientation in these adjacent sections. $C C$, corpus callosum. Scale bar, $100 \mu \mathrm{m}$. 

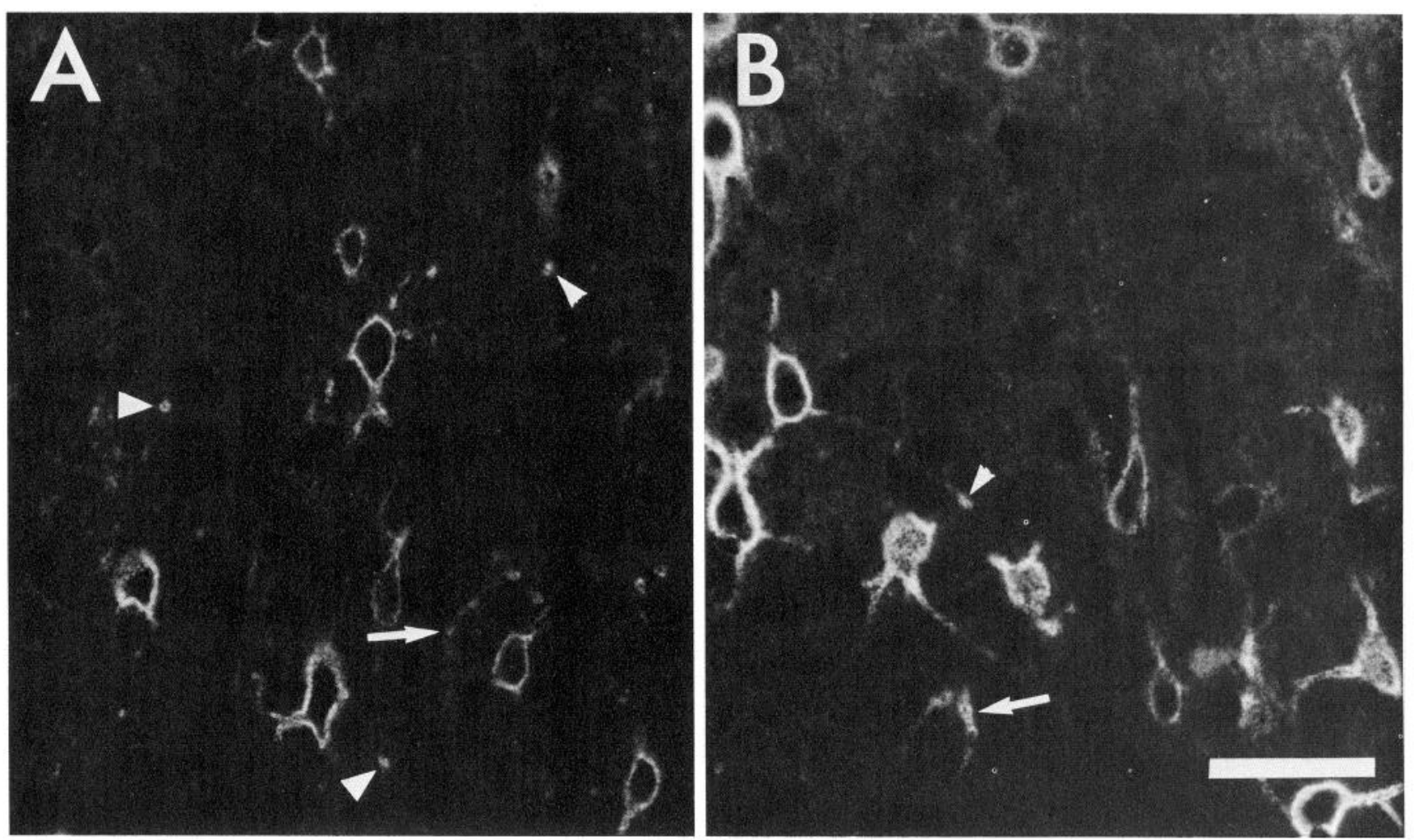

Figure 3. Immunofluorescent distribution of Tor 23 binding in lamina IV of motor cortex $(A)$ and somatosensory cortex $(B)$. The frequency of Tor 23 neurons varies between different regions of the isocortex. Labeled somata are most abundant in somatosensory cortex, followed by motor cortex. Note irregular orientation, morphology, and dendritic array of stained neurons. Finely stained threads (arrows) and small-diameter profiles (arrowheads) are presumptive processes. Scale bar, $50 \mu \mathrm{m}$.

CNS neurons in the rat brain and extends this finding by reporting the complete distribution pattern of the cell population labeled with Tor 23 in the entire brain and spinal cord of the rat.

\section{Materials and Methods}

Animals and tissue preparation. The material used in this study was obtained from adult Sprague-Dawley rats. Immunocytochemistry was performed on $10-\mu \mathrm{m}$-thick cryosections taken from formaldehyde-perfused animals. The details of our protocol have been published previously (Kushner, 1984). At intervals through each brain, groups of adjacent sections were taken and stained with the antibodies Tor 23 and sv48, with cresyl violet, and for AChE activity (using the procedure described by Paxinos and Watson, 1982). The sampling intervals were chosen in 2 ways, as a constant interval of sampling and to procure particular regions.

Monoclonal antibodies. Tor 23 is from a large collection of monoclonal antibodies generated to Torpedo cholinergic synaptosomes. Details of the preparation of immunogen, immunization, and fusion have been described previously (Kushner, 1984). Hybridoma culture supernatant was used for the present investigations.

The antibody sv48 is a monoclonal antibody that marks synaptic vesicles (Matthew et al., 1981). Culture supernatant was used.

Immunocytochemistry. Tor 23 was localized to rat CNS tissue using both the immunoperoxidase and the immunofluorescence techniques. While the peroxidase system provides permanent slides that are easy to orient and analyze at very low to high magnifications, it is sometimes not as sensitive as fluorescence. In addition, nonspecific binding and false positives are sometimes observed with peroxidase localization because of the presence of endogenous peroxidases in particular CNS tissues (observed and discussed by others, e.g., Houser et al., 1983). Fluorescent localization reveals surface-immunoreactive neuronal processes and somata, even when those stained neurons are situated in an area of densely labeled fibers and terminals (see Fig. 7). With immunofluorescence, however, orientation and examination at low magnifi- cation is not as straightforward as with peroxidase. For these reasons, we employed both techniques in this study.

The protocol for immunolocalizations has been described previously (Kushner, 1984). The second-antibody reagents were fluorescein-conjugated anti-mouse immunoglobulins (the high-fluorescent product; Antibodies Inc., Davis, CA), an avidin-biotin-peroxidase second-antibody system (Vectastain; Vector Labs, Burlingame, CA), and a peroxidaseantiperoxidase system (PAP; Biogenex Labs, Dublin, CA). The peroxidase was visualized using 3'3-diaminobenzidene (DAB). Enhancement techniques for the peroxidase localization were sometimes used. They included a double cycle of the final 2 reagents prior to the DAB treatment and poststaining with $0.1 \%$ osmium tetroxide.

Controls for immunocytochemistry. Control tissue, examined for the effects of fixation, included brains of unperfused animals and those of animals perfused with saline alone. The controls for the immunocytochemical reactions included sections incubated with no primary antibody, nonreactive primary antibodies and with antibodies that bound in patterns distinctly different from that of Tor 23 .

Microscopy. The tissue was examined with a Zeiss Ultraphot II microscope equipped for epi-illumination and Nomarski optics.

Data evaluation and analysis. A total of 10 rats was used for multiple examinations in all areas. In addition to Tor 23 staining, adjacent sections were stained for Nissl substance and for AChE activity, both of which served to delineate cytoarchitectural features and were particularly useful since they are used in the atlases of Paxinos and Watson $(1982,1986)$. In addition, some adjacent sections were stained with sv48, a monoclonal antibody to synaptic vesicles (Matthew et al., 1981), which served to demark neuropil regions.

To determine the average size of Tor 23-stained perikarya, 10 cells/ region were measured with an ocular micrometer. The size of the cell soma was determined by measuring the longest axis through the nucleolus and the line perpendicular to the longest axis, also through the nucleolus.

To determine the frequency of Tor 23-labeled neurons in each region, sections counterstained with cresyl violet were examined. The number of Tor 23-stained somata was divided by the total number of Nissl- 
3040 Stephenson and Kushner - Tor 23-Immunoreactive Neurons in the Rat CNS
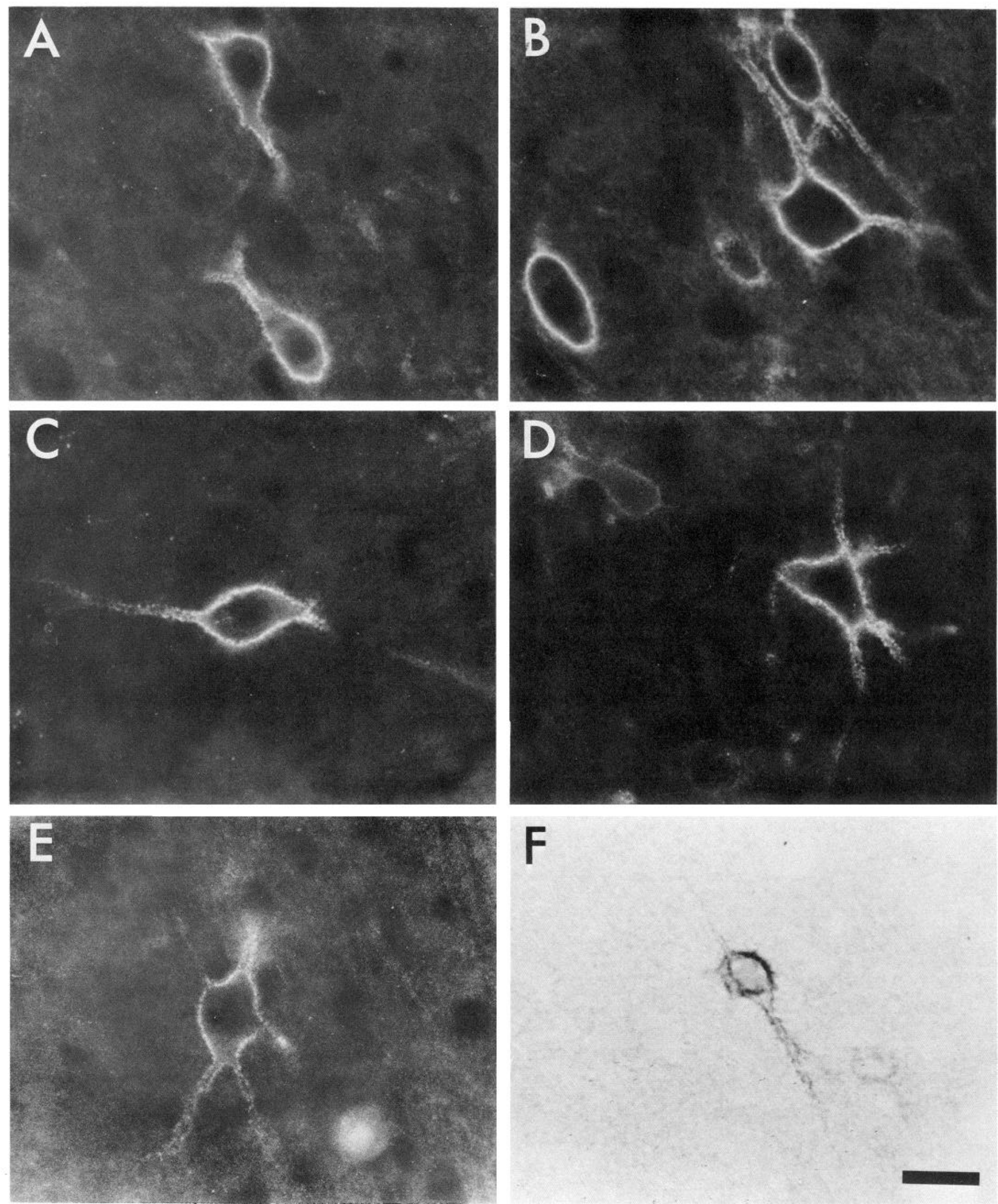

Figure 4. Tor 23-immunoreactive neurons are similar throughout the isocortex. $A, B$, Somatosensory cortex. $C$, Motor cortex. $D$, Cingulate cortex. $E$, Striate cortex. $F$, Auditory cortex. Fluorescent $(A-E)$ and peroxidase $(F)$ reaction products are deposited all along the entire perimeter of the perikarya and their processes. In each field there are unlabeled somata, most evident in $B$. Labeled neurons do not display a pyramidal configuration, nor do they possess obvious apical and basal dendrites. Processes appear aspinous. Note unstained, dark nucleus in each stained soma. Scale bar, $20 \mu \mathrm{m}$. 
stained somata in a particular field. The fields varied according to the anatomical region; i.e., in areas such as the facial motor nucleus (7; Paxinos and Watson, 1982), in which there are distinct anatomical boundaries, only those cells within the nucleus were counted. In isoand allocortices, the frequency was determined by counting the total number of Tor 23-stained neurons relative to the number of Nisslstained somata in a field inclusive of all laminae or layers (200 or more cells per field). In certain areas that were very diffuse and where stained cells were rare, the frequency is expressed as number of cells per coronal section. In each instance, the determined frequency represents an average of several independent countings.

The rat brain stereotaxic atlases of König and Klippel (1974) and Paxinos and Watson $(1982,1986)$ were used for the orientation and identification of structures. In addition, the following articles were consulted: Pelers and Jones, 1984; Zilles, 1985; Valverde, 1986 (cerebral cortex); Donoghue and Wise, 1982 (motor cortex); Games and Winer, 1988 (auditory cortex); Ruth et al.. 1982 (entorhinal cortex); Amaral, 1978; Seress, 1978; Seress and Pokorny, 1981 (hippocampus); Armstrong et al., 1983; Houser et al., 1983; Levey et al., 1983; Mesulam et al., 1983 (septum/diagonal band); Reid et al., 1975 (red nucleus); Rye et al., 1987 (pedunculopontine tegmental nucleus); Sotelo and Palay, 1968 (vestibular system); Osen, 1969; Harrison and Feldman, 1970; Brawer et al., 1974; Wehster, 1985 (brain stem auditory structures); Navaratnam and Lewis, 1970; Barber et al., 1984 (spinal cord).

\section{Results}

Tor 23 bound selected somata, neuropil regions, and fiber tracts in the adult albino rat CNS. Immunopositive somata displayed stain all along the apparent cell surface, with little or no immunobinding to the cytoplasm, although presumably Tor 23 antigen is synthesized there. In this study, we catalog the regions with immunoreactive somata. Cryosections were taken throughout the brain and spinal cord and were immunostained with fluorescence and peroxidase. For orientation purposes, adjacent sections were stained with cresyl violet, for AChE activity, and with sv48, a monoclonal antibody to purified synaptic vesicles that demarks neuropil regions (Matthew et al., 1981). An atlas of the distribution of Tor 23-positive somata in the rat brain and spinal cord is presented diagrammatically in Figure 1.

\section{Forebrain}

Isocortex. A field of somatosensory cortex stained for Tor 23 illustrates the laminar distribution of stained neurons (Fig. 2). An examination of the isocortex from its rostral to caudal extent revealed immunoreactive somata, primarily in laminae II-IV, and, to a lesser extent, in laminae V and VI; $75 \%$ of all cortical immunoreactive neurons were present in laminae II-IV. Lamina I did not contain reactive neurons but did display intense antibody-specific stain. Lamina I costained for synaptic vesicles with sv 48 .

The frequency of Tor 23-positive neurons varied according to the cortical area. Stained cells were most abundant in the somatosensory cortex (Fig. $3 B$ ) and the motor cortex (Fig. $3 A$ ), where they respectively represented $7 \%$ and $5 \%$ of the total neurons; the cingulate, retrosplenial, and auditory cortices contained fewer labeled neurons (2-3\%), while, to the visual cortex, immunopositive somata comprised only $1 \%$ or less of the total neurons.

In each isocortical area, the immunopositive neurons displayed a characteristic staining pattern and morphology. All positive cells were stained along the apparent perimeter of the soma and its processes; immunoreactivity was not detectable in the cytoplasm (Fig. 4). Somata were large to medium-sized (average size, $20 \times 18 \mu \mathrm{m}$ ) and multipolar (3-5 processes), with visibly stained processes extending up to $25 \mu \mathrm{m}$ from the soma. Neither the soma nor its processes were positioned in a constant orientation, although occasionally vertically oriented processes and single bipolar neurons were observed. Somata did not possess a shape typical of pyramidal cells, i.e., a conical morphology. The processes appeared to be aspinous. Thus, everywhere in the isocortex, Tor 23 defined a category of neurons that were nonpyramidal, smooth, and polymorphic.

Allocortex. Tor 23 bound as a dense outline along the apparent perimeter of selected neurons in all areas of the hippocampal formation. The subiculum and entorhinal cortex contained immunorcactive somata that had a morphology like that of the Tor 23-stained neurons of the isocortex. They represented only a small percentage of the total neurons, accounting for approximately $4 \%$ of neurons in the subiculum, presubiculum, and parasubiculum and $2 \%$ of neurons in the caudal extent of the entorhinal cortex. Tor 23-positive neurons were not found in the rostral area of the entorhinal cortex.

In the hippocampus, Tor 23 stained rare and select cells. As in the cortex, stained somata were labeled all along the perimeter of the perikarya and their apparent processes, with no obvious labeling occurring in the cytoplasm (Figs. 5,6). Immunopositive somata averaged $20 \mu \mathrm{m}$ in diameter and, for the most part, appeared pyramidal-shaped in the CA regions and basket celllike in the dentate gyrus. Stained neurons had varying numbers of visibly stained arborizations. At this light-microscopic level of examination, these processes appeared aspinous, both proximally and distally, although we could not rule out the possibility that spines were present but unstained. In the ventral hippocampus, stained neurons occurred in locations consistent with those observed in the dorsal hippocampus, but were fewer in number. In the CA 1 and $\mathrm{CA} 3$ regions of the dorsal hippocampus, Tor 23 localized to rare neurons, representing less than 1\% of all somata (Fig. $5, A-C, F, G$ ). In the dorsal CA1, labeled neurons were present in equal amounts in the pyramidal celi layer and in the stratum oriens, while stained cells were only occasionally observed in the stratum radiatum. Within the pyramidal layer, immunoreactive neurons were typically found at the edges of the layer proper (Fig. 5, $A-C$ ); many displayed a pyramidal morphology. Some positive neurons of stratum oriens and stratum radiatum likewise had pyramidal shapes and may have been ectopic pyramidal cells. Stained somata also occurred in the stratum oriens just deep to the alveus. Processes from neurons with this location were sometimes observed to extend directly into the alveus, which in turn contained other Tor 23-positive fibers. Generally, in CA1, stained processes occurred in the stratum oriens but not in the stratum radiatum.

In CA3 of the dorsal hippocampus, immunoreactive neurons were fewer in number than in CA1 (CA3: 1-8 neurons/hemisection; CA1: 10-25 neurons/hemisection). Like the CA1 neurons, the CA3-positive neurons were detected within the pyramidal cell layer itself (Fig. $5, F, G$ ) and within the adjacent layers, strata radiatum and oriens. Unlike in CAl, immunoreactive neurons of CA3 did not appear to extend stained processes into an adjacent stratum.

In the presumptive CA 2 region, as defined by Lorente de Nó (1934) and included in the atlases by Paxinos and Watson (1982, $1986)_{2}$ a strikingly different category of stain was observed, in that all neurons of the pyramidal layer appeared to be stained with For 23 (Fig. 5, D, E). Because there appeared to be specific staining in the intercellular spaces, labeled processes extending from the CA2 neurons were difficult to observe. One presumptive process is shown in Figure $5 E$ (at arrows). In contrast, labeled neurons were fewest in the CA4 region. The CA4 py- 

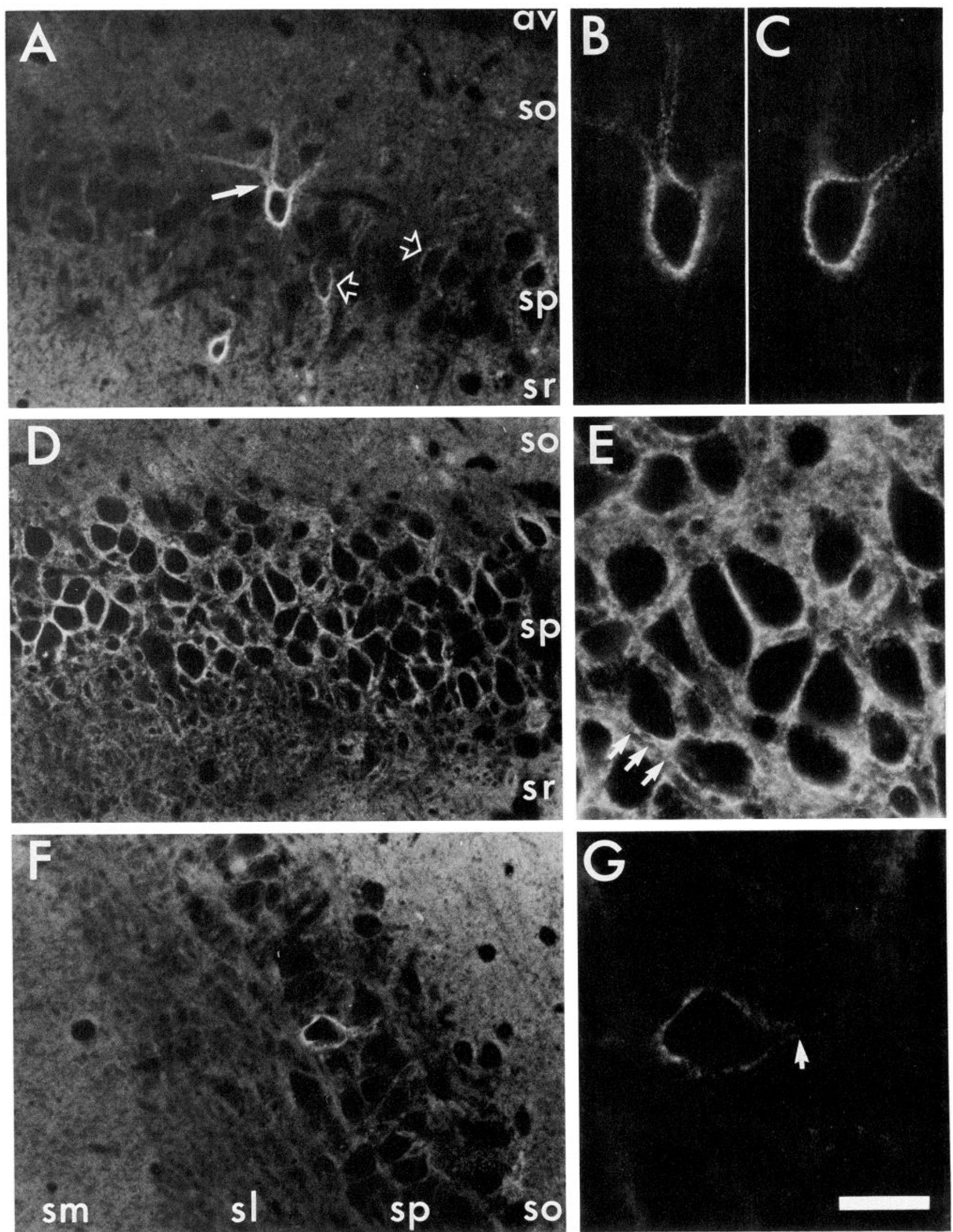

Figure 5. Immunofluorescent localization of Tor 23 in the hippocampus proper. Tor 23 differentially labels pyramidal neurons of the hippocampus. The pyramidal cell layers of CA1 $(A-C), \mathrm{CA} 2(D, E)$ and $\mathrm{CA} 3(F, G)$ are illustrated in this area of dorsal hippocampus. Photographs on the right are high-power micrographs taken from the center of the field shown on the left. $A$, In CA1, the stained cell at filled arrow extends processes into stratum oriens. This neuron was photographed at 2 different planes of focus $(B, C)$ to reveal a somewhat 3-dimensional image of its labeled soma 
ramidal cell layer contained 0-3 stained neurons/hemisection (Fig. 6, $A, C$, open arrow). Within the hilus, Tor 23 localized to neurons in the inner molecular layer (Fig. 6A) and outer molecular layer (Fig. 6C). These cells were multipolar, mediumsized $(18-25 \mu \mathrm{m})$, and few in number. They may correspond to displaced neurons of the CA4 layer, described by Amaral (1978).

The dentate gyrus contained Tor 23-positive neurons within the granule cell layer. Stained somata were relatively large, measuring $20 \times 35 \mu \mathrm{m}$, and displayed extensive dendritic arborizations that extended into the molecular layer (Fig. 6B, arrows) and never into the polymorphic layer. Stained processes were traced up to $180 \mu \mathrm{m}$ from an individual perikaryon. Similarstained somata were located within the polymorphic layer adjacent to the granule cell layer. On the basis of the perikaryal size and position and the location of dendritic arborizations, immunoreactive cells in this region may be pyramidal basket cells (Seress, 1978; Seress and Pokorny, 1981). The position, size, morphology, and dendritic arborization of the neuron in Figure $6 B$ (long arrow) are similar to those observed in a Type I basket cell, as defined by Seress and Pokorny (1981). In addition, the nuclei of Tor 23-positive neurons within the dentate gyrus, observed with Nomarski optics, typically occupied no more than two-thirds of the cell body and contained only one nucleolus, characteristics of basket cells, as distinct from granule cells (Seress and Pokorny, 1981). Tor 23 did not stain all pyramidal basket cells; sections counterstained with cresyl violet revealed neurons with a similar appearance, that is presumptive basket cells, which were unstained. Moreover, stained cells with this location and morphology were too few in number (2-5 neurons/hemisection) to correspond to all basket cells (Seress and Pokorny, 1981).

The final cortical area to be presented is the piriform cortex, another allocortical structure. This area distinguished itself in that Tor 23 localized to neuronal perimeters in a background of specific, regional stain. With this backdrop of regional stain, somata were most easily observed with immunofluorescence, with some cells staining more clearly than others (Fig. $7 A$, arrows). Adjacent sections treated with sv48, which binds synaptic vesicles, stained heavily in the piriform cortex and indicated that this was a neuropil region (Fig. $7 B$ ). Other regions of the brain displayed similar Tor 23 neuropil staining and will be investigated in future studies.

Septum. Tor 23 labeled neurons of the medial and lateral septal nuclei and neurons of the diagonal band. Stained neurons of the medial and lateral septal nuclei are presented in Figure 8. In both septal nuclei, stained somata (Fig. 8, $A, B$, filled arrows) were adjacent to unstained somata (Fig. $8, A, B$, open arrows) and were situated in a background of densely staining regions that were also positive for synaptic vesicles. In the medial septal nucleus, Tor 23-positive neurons were small, 12-15 $\mu \mathrm{m}$ in diameter (Fig. $8 A$ ). In the lateral septum, Tor 23-positive neurons were somewhat larger, measuring $15-20 \mu \mathrm{m}$ in diameter, and were located in the dorsal and ventral aspects, adjacent to the lateral ventricle, but not in the intermediate portion of this nucleus (Fig. $8 B$ ). Larger neurons of the lateral septal nucleus did not immunostain (Fig. $8 B$, open arrow). Neurons of the vertical limb of the diagonal band were immunolabeled, but represented a very small proportion of the total neurons (1-5 cells/section). The hindlimb of the diagonal band had even fewer Tor 23-reactive somata.

Striatum and thalamus. Neuronal cell surface staining was not observed in the corpus striatum (Fig. $8 \mathrm{C}$ ) or the thalamus (Fig. $8 D$ ). Rare neurons, however, in the caudate putamen, the globus pallidus, the substantia innominata, and thc nuclcus basalis ( 15 cells/forebrain section in all of the regions combined) did contain stained granule-like structures within their cytoplasm and appeared to be Golgi components (Fig. 8C, inset). The appearance of the epitope within these structures may be due to a lack of surface processing of the antigen in these neurons. This possibility will be addressed in future studies. One other exception was the presence of a few somata ( $1-15 /$ section) dimly labeled on their perimeters in the reticular thalamic nucleus in 3 rats examined. The absence of significant surface immunoreactivity in these large forebrain areas served to emphasize the specificity of Tor 23 staining elsewhere.

Hypothalamus. In the hypothalamus, immunoreactive neurons were present in 2 distinct nuclei, the supraoptic nucleus and the magnocellular paraventricular nucleus, those nuclei which innervate the posterior lobe of the pituitary gland. Curiously, the tightly packed cells of these nuclei displayed immunoreactivity similar to the staining observed in the CA2 pyramidal cell layer of the hippocampus. As in CA2, all neurons were immunopositive and existed in a high density of specific stain. Unlike the staining in CA2, Tor 23 stained the intersomata spaces of the supraoptic and paraventricular nuclei in a punctate fashion. This was most obvious in the paraventricular nucleus, where small, uniformly sized granules were evident. This distinctive granule-like stain was not observed elsewhere in the nervous system. Positive neurons were not found in any other hypothalamic nucleus.

\section{Cerebellum, midbrain, and hindbrain}

As in the forebrain, Tor 23 immunoreactivity in the cerebellum, midbrain, and hindbrain was found to outline selected neurons. The midbrain contained relatively few immunoreactive somata, while the hindbrain displayed many more. The stained nuclei displayed distinctly different staining patterns: lightly stained neurons and intensely stained neurons. Somata shapes were typically either spherical, such as those of the deep cerebellar nuclei, or angular, such as the Deiter's neurons.

Cerebellum and related nuclei. All somata of the deep cerebellar nuclei were immunoreactive, displaying a high intensity of antibody staining (Fig. 9A). Other labeled structures in these nuclei were circular profiles, more than likely cross sections of the large-diameter proximal neurites that typically are found on these neurons, and smaller, stained patches, which may be more finely stained processes. Tor 23 immunoreactivity was not detected in any of the cortical layers of the cerebellum.

\footnotetext{
and processes. In $A$, note other neurons that are dimly stained within the pyramidal layer (open arrows). Stratum radiatum (sr) contains a strikingly labeled soma. $D$, In the CA2 region, all pyramidal cells are stained. Stain is present not only on the apparent perimeter of somata but also in the intercellular spaces $(E)$. A presumptive process is depicted at arrows $(E) . F, G$, In CA3, a neuron displays Tor 23 stain along its perikaryon and primary process $(G$, arrow). av, Alyeus; $s p$, stratum pyramidale; so, stratum oriens; $s l$, stratum lucidum moleculare; $s m$, stratum moleculare. Scale bar, $50 \mu \mathrm{m}(A, D, F) ; 20 \mu \mathrm{m}(B, C, E, G)$.
} 


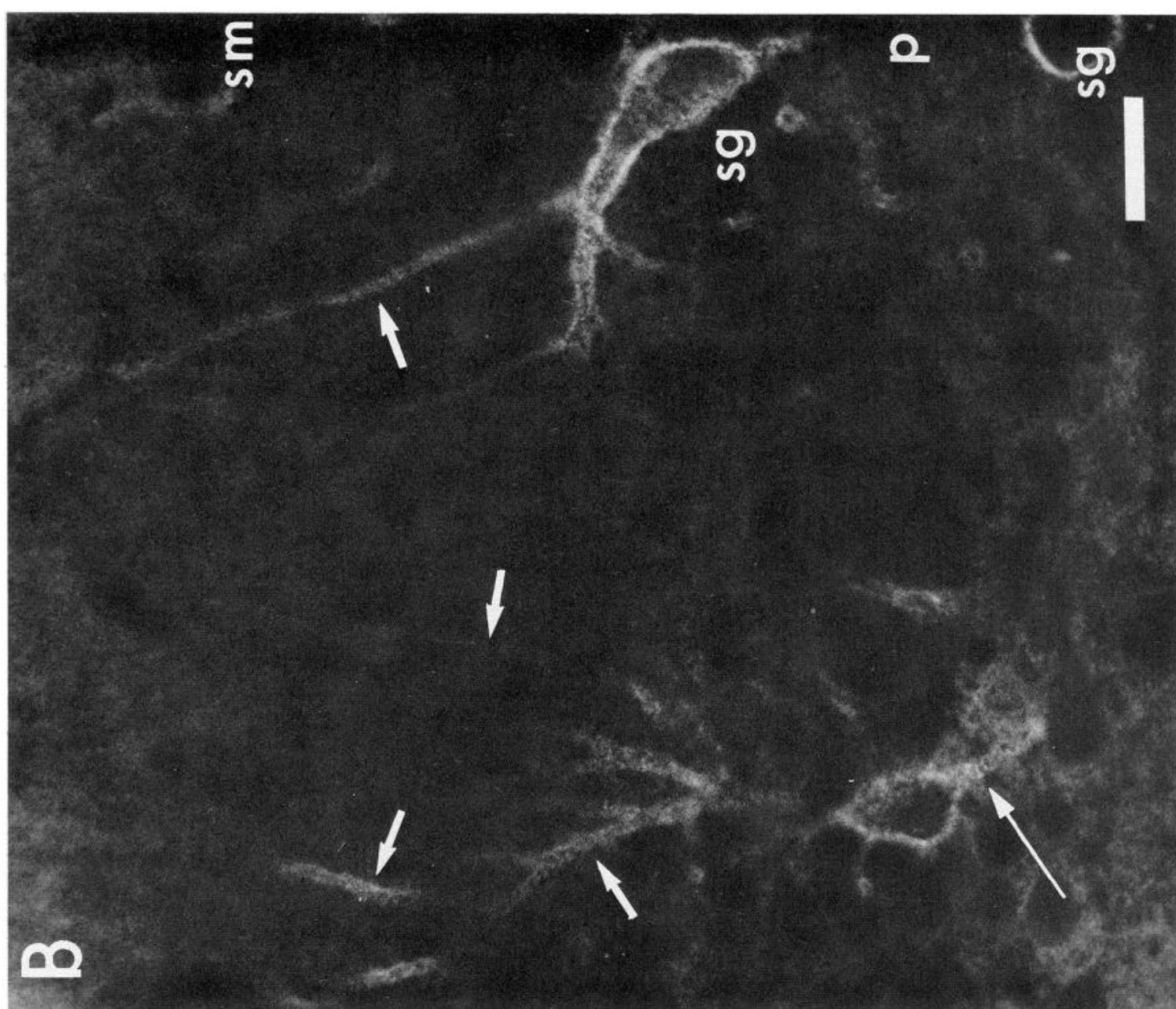

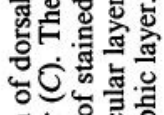

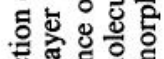
耐

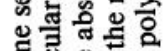
태용 w 눈 옹

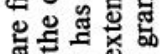

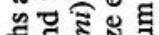

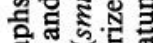
跑的。 药

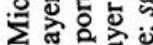

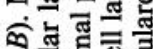
局 두을 늠 范范要 政 घ․ 응 일

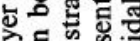
త్ $\leqq$ क 节吉 8 吃 늑 놏일 踏击 क वै 实

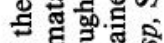
명양 के

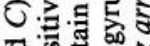

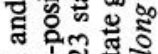<smiles>C#CCCC(C)CC(C)S(=O)(=O)c1ccccc1</smiles>

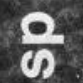

$2 y$

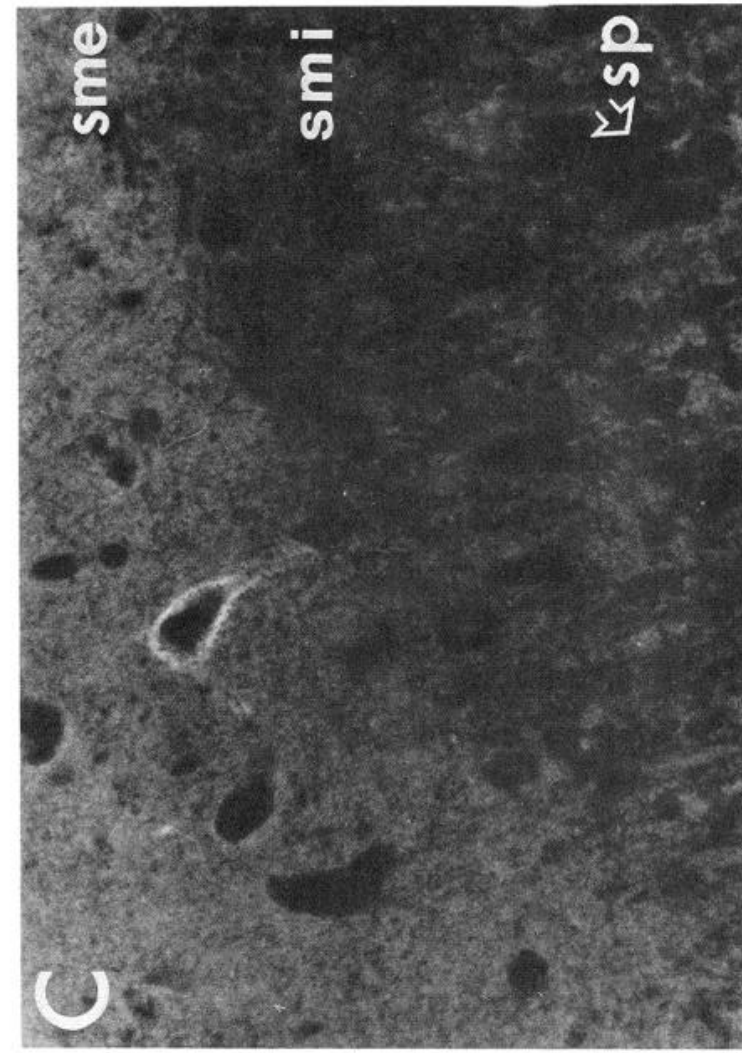

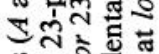
ㅎํำ 사을

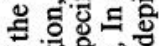
प्ठक क्ष 㲅宁 ํㅗㅇำ 글

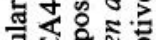
을 응ㅎㅀ

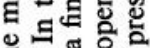

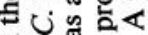

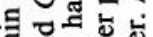
สญ氜

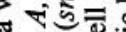
สำ 언르원

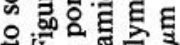

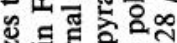
चัष्ठ 은 원하 m

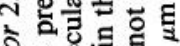
○ - ह छ

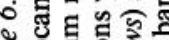

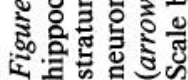



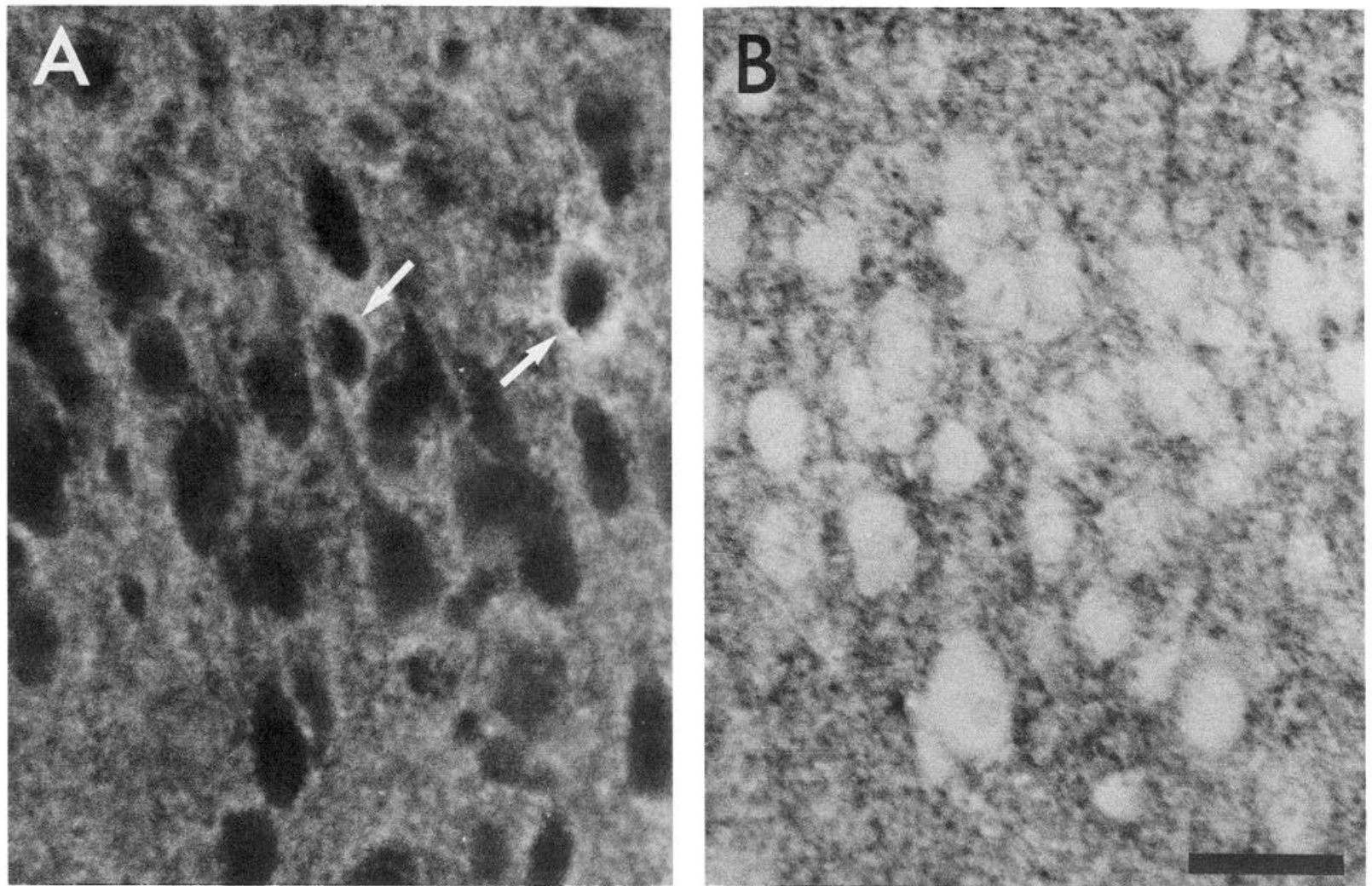

Figure 7. The piriform cortex stained with Tor 23 immunofluorescence $(A)$ and synaptic vesicle antibody (sv48) immunoperoxidase (B). A, Tor 23 binding is present on the apparent perimeter of some somata (arrows) and is also strongly localized to the nonperikaryal space. Since the cells are situated in such dense specific stain, it is not possible to determine at this level of resolution whether Tor 23 binds the perimeter of all neurons. $B$, A near-adjacent section stained with sv48, a monoclonal antibody to synaptic vesicles (Matthew et al., 1981) displays a dense matrix of specific stain similar to that observed in $A$, indicating this region is neuropil. Unlike Tor $23(A)$, somata are not stained on their perimeter by sv48. Scale bar, $30 \mu \mathrm{m}$.

In the red nucleus, Tor 23 bound the perimeter of neurons within both the magnocellular and parvocellular components. Figure $10 \mathrm{~A}$ is a photomicrograph of immunoreactive somata and their processes within the parvocellular red nucleus. Polymorphic neurons, medium- to large-sized $(20 \times 30 \mu \mathrm{m})$, displayed immunoreactivity all along their entire apparent surfaces. The dispersed cells of this nucleus were not all positive for Tor 23 binding; approximately $30 \%$ of the somata were immunostained. The appearance of the surface stain was uniform and intense on the neurons of the parvocellular region and uniform but significantly less intense on the neurons of the magnocellular region.

Neurons of the pontine reticulotegmental nucleus were strongly stained. The nucleus, located dorsal to the medial lemniscus, at the level of the cerebral aqueduct, consisted of oval and fusiform-shaped perikarya, all of which bound Tor 23. Staining in this region appeared very similar to that of the deep cerebellar nuclei to which it is reciprocally connected. The reticulotegmental nucleus was the most outstanding region of Tor $23 \mathrm{im}$ munostain in the pons.

In the caudal medulla, there was a well-circumscribed column of strongly positive neurons in the ventrolateral quadrant that continued throughout the extent of the elongated hypoglossal nucleus (Fig. 11A). This region corresponded to the lateral reticular nucleus, which has connections with the cerebellum. The stained column proceeded into the caudalmost extent of the brain stem, i.e., at the level of and beyond the nucleus ambiguus. Caudally, the column extended dorsomedially, in a continuous crescent, beyond the lateral reticular nucleus and joined into the ventral component of the reticular nucleus of the medulla, which contained stained neurons and is described below. Stained neurons of the lateral reticular nucleus were multipolar, with distinctly angular somata. They comprised most $(80 \%)$ of the neurons in the nucleus.

Reticular formation. Tor 23 bound selected neurons within the reticular formation. Relative to other nervous system areas, the rat reticular nuclei are structurally complex and sometimes lack distinct cytoarchitectural boundaries (Andrezik and Beitz, 1985). In spite of this complexity, Tor 23 staining in this region was precise and predictable, perhaps indicating organizational features not observed with other histological, histochemical, and immunochemical techniques.

In the pons, intensely stained somata were located immediately lateral to the decussation of the superior cerebellar peduncle at the level of the cerebral aqueduct, within the region corresponding to the pedunculopontine tegmental nucleus, a major cholinergic area. Stained neurons in this area were medium-sized, angular or elongate in shape, and multipolar (Fig. $11 C$ ). The number of neurons stained appeared to be fewer than that demonstrated with choline acetyltransferase immunoreactivity (Rye et al., 1987).

Beginning in the pons, scattered, stained cells were prominent in the central core. In the pontine tegmentum, these cells were present in the caudal, but not in the oral, subdivision of the pontine reticular nucleus. In the rostral medulla, stained neurons within the central core became even more apparent: they were 

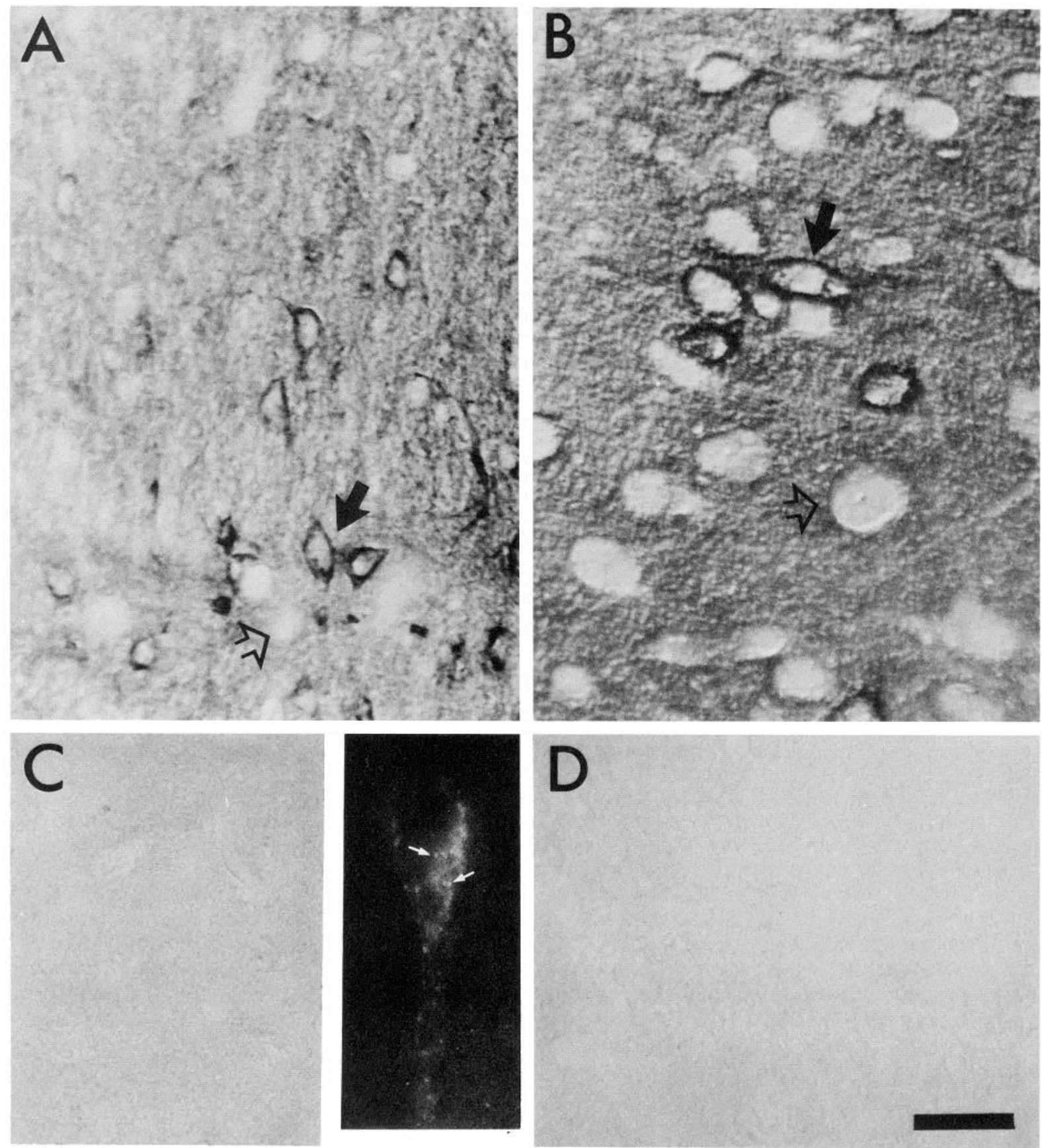

Figure 8. Tor 23 peroxidase localization in the septal nuclei $(A, B)$, in the corpus striatum $(C)$, and the central medial thalamus $(D)$. $A$, In the medial septal nucleus, Tor 23 outlines small neurons. $B$, In the lateral septal nucleus, larger, stained perikarya are observed. In both septal nuclei, stained neurons (filled arrows) are situated in a dense matrix of specific stain. Unstained somata are observed in each region (open arrows). $C$, $D$, With immunoperoxidase, the corpus striatum $(C)$ and the thalamus $(D)$ have no detectable Tor 23 staining and appear the same as control sections incubated with no primary antibody. With immunofluorescence, at high magnification, very rare Tor 23-positive neurons are observed in the striatum $(C$, insert $)$. Staining of 'hese rare striatal neurons appears as punctate granules within the cytoplasm $($ arrows $)$. Scale bar, $30 \mu \mathrm{m}(A, B) ; 38$ $\mu \mathrm{m}(C, D) ; 17 \mu \mathrm{m}(C$, insert $)$.

more strongly stained and more numerous. As what appeared to be a caudal extension of this central group, the gigantocellular reticular neurons, which are readily distinguished on the basis of size and the density of Nissl substance in counterstained sections, and which lie within the central core, were stained (Fig. $11 B$ ). Just lateral to the gigantocellular neurons, but still within the central core, there were other, smaller immunoreactive neurons within the region of the parvocellular reticular nucleus.

Figure 9. Tor 23 peroxidase-labeled neurons in a deep cerebellar nucleus $(A)$, the ventral cochlear nucleus $(B)$, and the lateral vestibular nucleus (C). $A$, In the nucleus interpositus, immunoreactivity is strongly deposited on all neurons, on the soma, and on proximal processes (large arrows). 

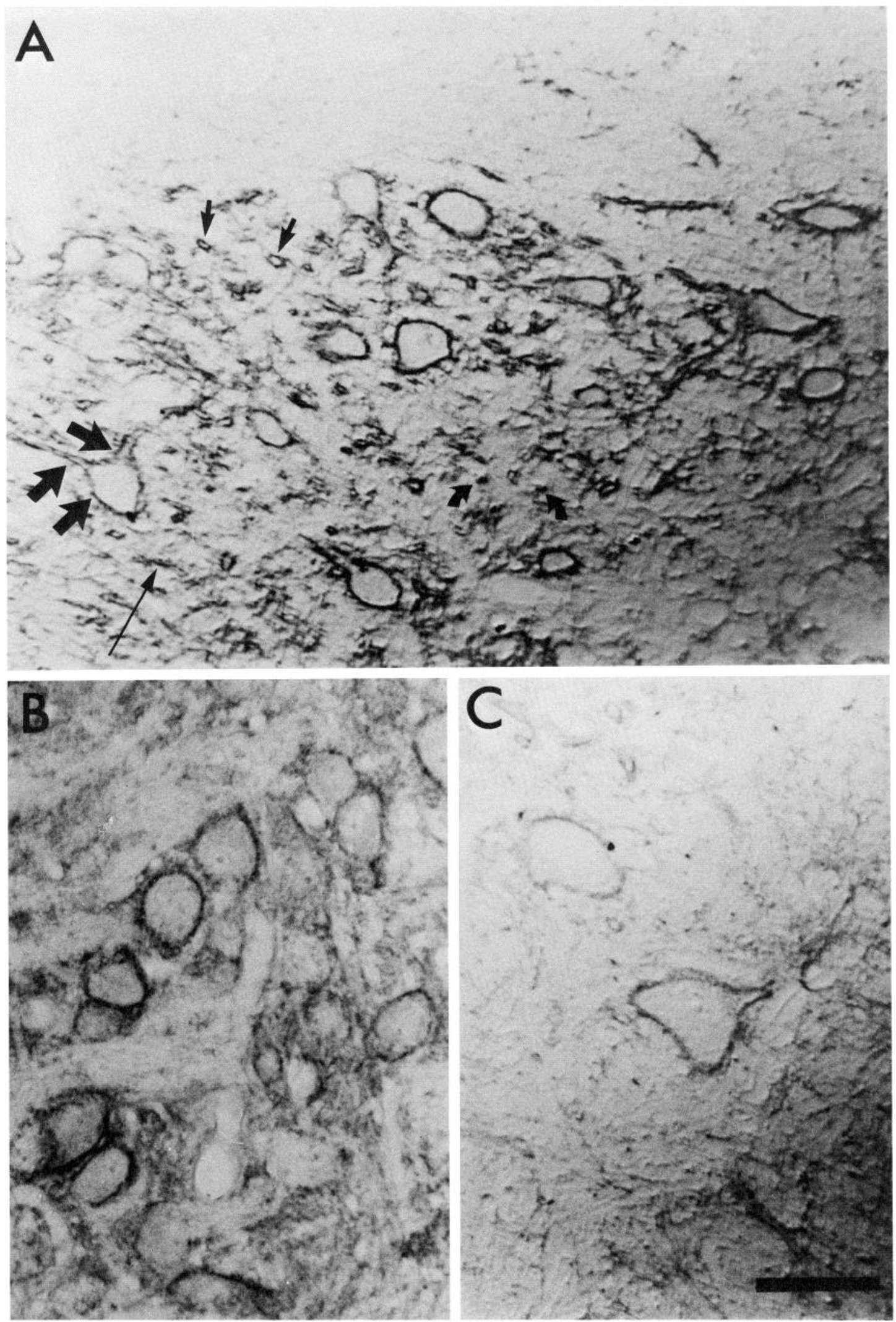

Peroxidase reaction product is also present on fine granules (curved arrows), threadlike profiles (long thin arrow), and circular profiles (small arrows). Cerebellar tissue adjacent to this nucleus is unstained ( $A$, dorsal portion). $B$, All neurons of the ventral cochlear nucleus except the granule cells display immunoreactivity on their apparent perimeter. Positive somata are mostly ovoid in morphology. $C$, In the lateral vestibular nucleus, Tor 23 immunoreactivity outlines the giant Deiter's neurons. The perikaryon in the center of the field measures $42 \times 55 \mu \mathrm{m}$ and displays antibodyspecific stain ubiquitously along its perimeter. The photomicrographs were made from the same tissue section (PW 36; Paxinos and Watson, 1982). Scale bar, $50 \mu \mathrm{m}$. 

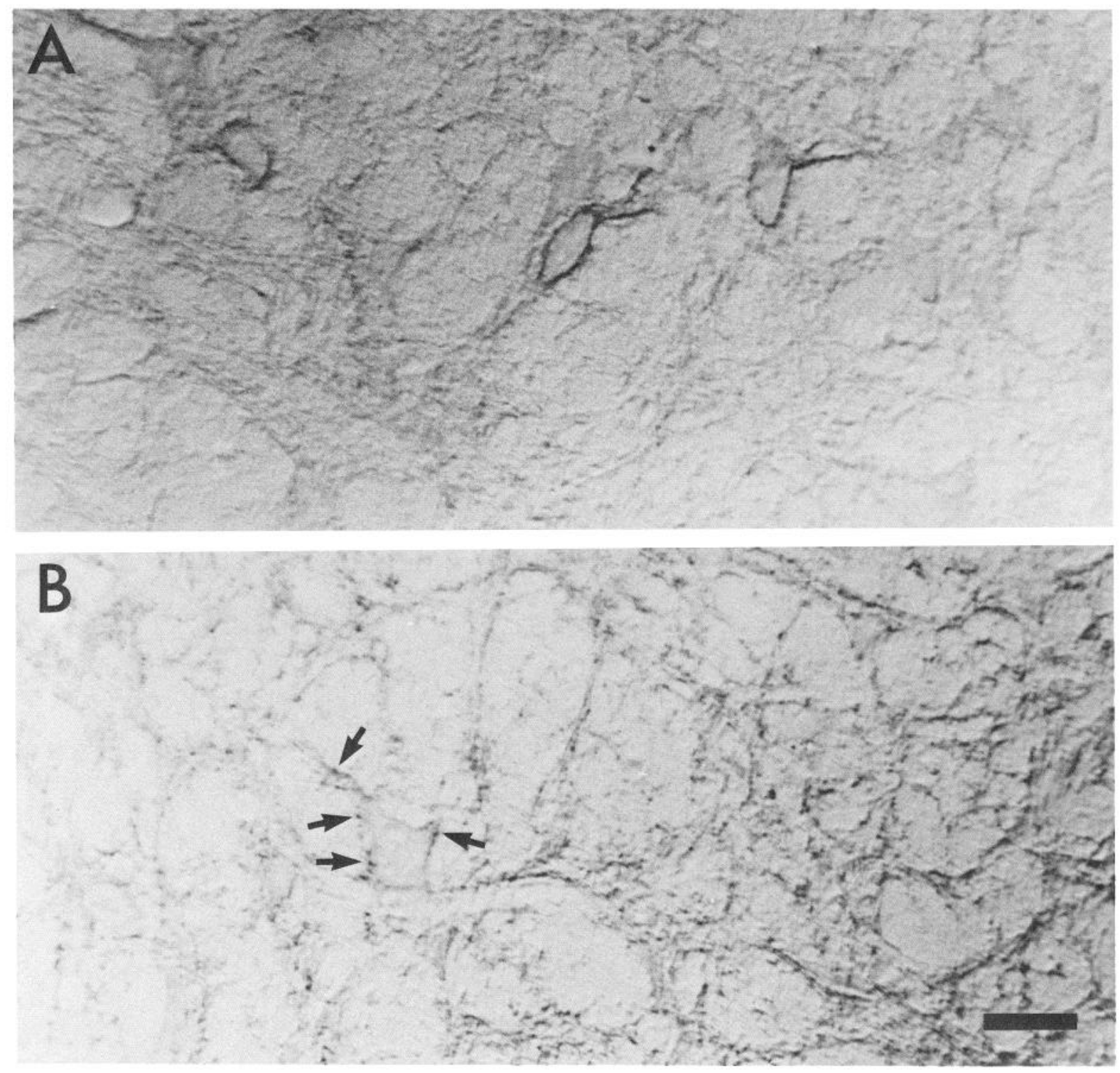

Figure 10. The red nucleus stained with Tor $23(A)$ and synaptic vesicle antibody, sv48 $(B)$ by immunoperoxidase. $A$, Tor 23 -immunoreactive neurons in the parvocellular red nucleus. Specific reaction product is deposited uniformly along the perimeter of somata and their processes. $B$, sv48 staining in the corresponding field of an adjacent section displays fine punctate granules, presumptive synaptic boutons, deposited on the apparent perimeter of a perikaryon and its processes (arrows). Synaptic vesicle stain, even when localized along neuronal perikarya $(B)$ differs markedly from the uniform deposition of Tor 23-specific stain $(A)$. Scale bar, $30 \mu \mathrm{m}$.

These latter somata were few in number and dimly stained. Finally, in the caudal medulla, prominently stained, large neurons similar to the gigantocellular neurons were present. They were located ventrally and medially, within the raphe obscurus, the paramedian reticular nucleus, and the ventral component of the reticular nucleus of the medulla. The neurons of this ventral component of the reticular nucleus appeared to join medially with the stained cells of the lateral reticular nucleus described above.

Eighth-nerve nuclei and related auditory structures. The ventral cochlear nuclei and the vestibular nuclei, afferent structures of the eighth cranial nerve, contained numerous Tor 23-immunoreactive neurons. In the ventral cochlear nucleus, virtually all somata were immunostained except for the granule cells, which were negative. Staining was present on small (14-18 $\mu \mathrm{m})$, medium $(18-30 \mu \mathrm{m})$, and giant $(35-40 \mu \mathrm{m})$ somata, which were ovoid or spherical in morphology (Fig. $9 B$ ). Specific examples were observed of octopus cells, globular cells, and cells of the cochlear nerve root. The dorsal cochlear nucleus was negative.

Several other auditory nuclei contained Tor 23-positive neurons: the superior and medial olivary nuclei, the trapezoid body nuclei, the ventral periolivary nucleus, the dorsal and ventral nuclei of the lateral lemniscus, and the inferior colliculus. Like the ventral cochlear nuclei, almost all somata of most of these nuclei were stained, although some nuclei were stained more heavily than others. Strongly stained nuclei included the trapezoid body nuclei, the ventral nucleus of the lateral lemniscus, and the superior olive. The dorsal nucleus of the lateral lemniscus and the inferior colliculus contained a few, lightly labeled somata. Stained neurons of the inferior colliculus were present in the more -medial aspect of the external component. In fact, the only auditory structure in the brain stem that did not have 

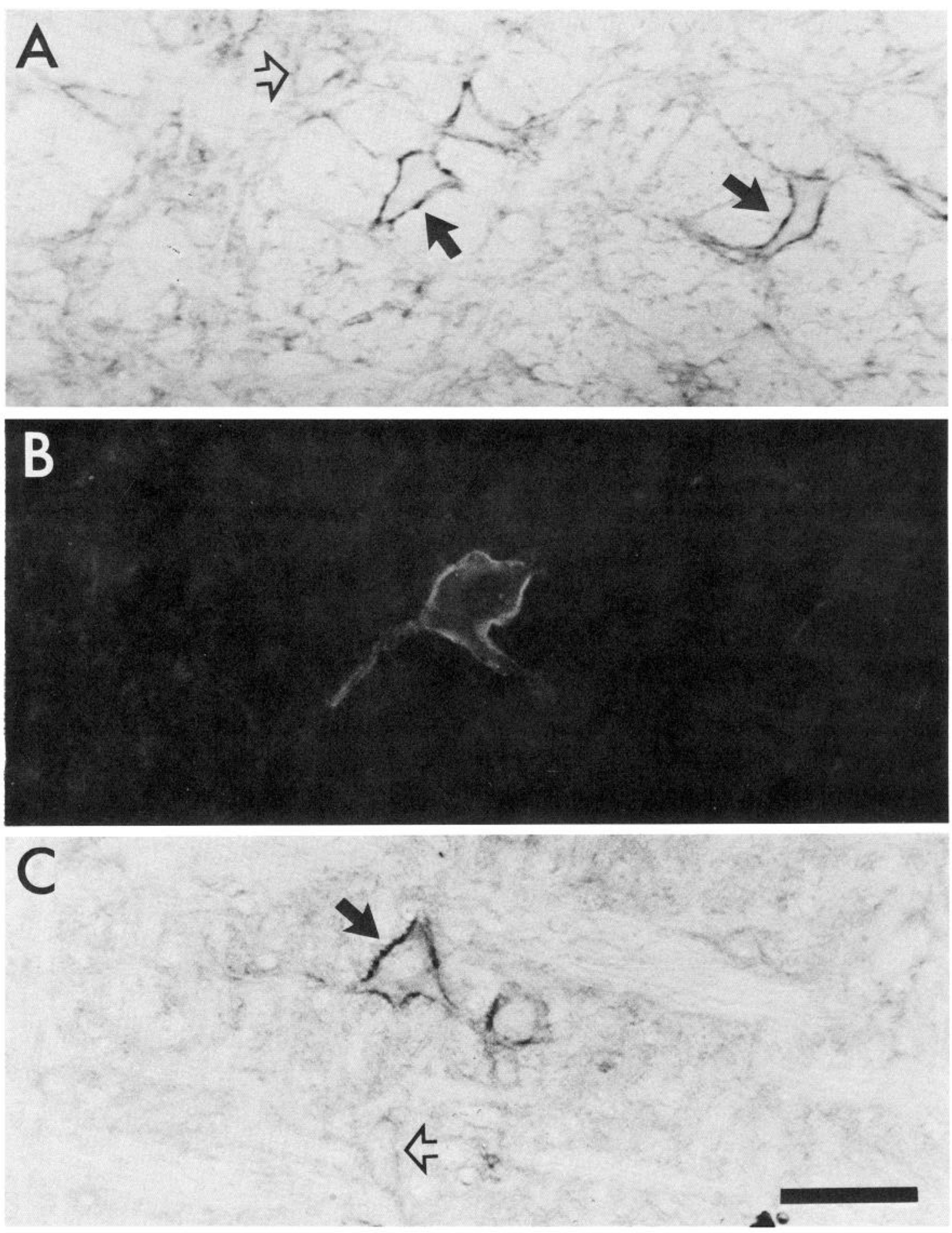

Figure 11. Tor 23 recognizes neurons of the reticular formation. A, The lateral reticular nucleus contains polymorphic neurons that display varying degrees of Tor 23 stain intensity. Large, multipolar, strongly labeled somata (filled arrows) are illustrated along with smaller, dimly labeled perikarya (open arrow). B, In the gigantocellular reticular nucleus, a large neuron (measuring $45 \times 35 \mu \mathrm{m}$ ) displays Tor 23 fluorescent reaction product on the apparent surface of its soma and two processes. $C$, The pedunculopontine tegmental nucleus contains somata, some of which are strongly stained (filled arrow); others are dimly stained (open arrow). Labeled neurons vary in size. Scale bar, $50 \mu \mathrm{m}$.

Tor 23-immunoreactive neurons was the dorsal cochlear nucleus.

In the vestibular nuclear complex, Tor 23 immunostained the giant neurons of the lateral vestibular nucleus, the Deiter's neurons (Fig. $9 C$ ). These neurons, significant for their large size $(40 \times 60 \mu \mathrm{m})$, were heavily stained all along their perimeter.
Other cells of the lateral vestibular nucleus, small and mediumsized neurons (15-30 $\mu \mathrm{m}$ in diameter), were observed in counterstained sections but lacked Tor 23 binding. The superior vestibular nucleus contained immunoreactive neurons that were small to medium-sized (15-25 $\mu \mathrm{m}$ in diameter) and accounted for approximately $75 \%$ of the total neurons in this nucleus. In 

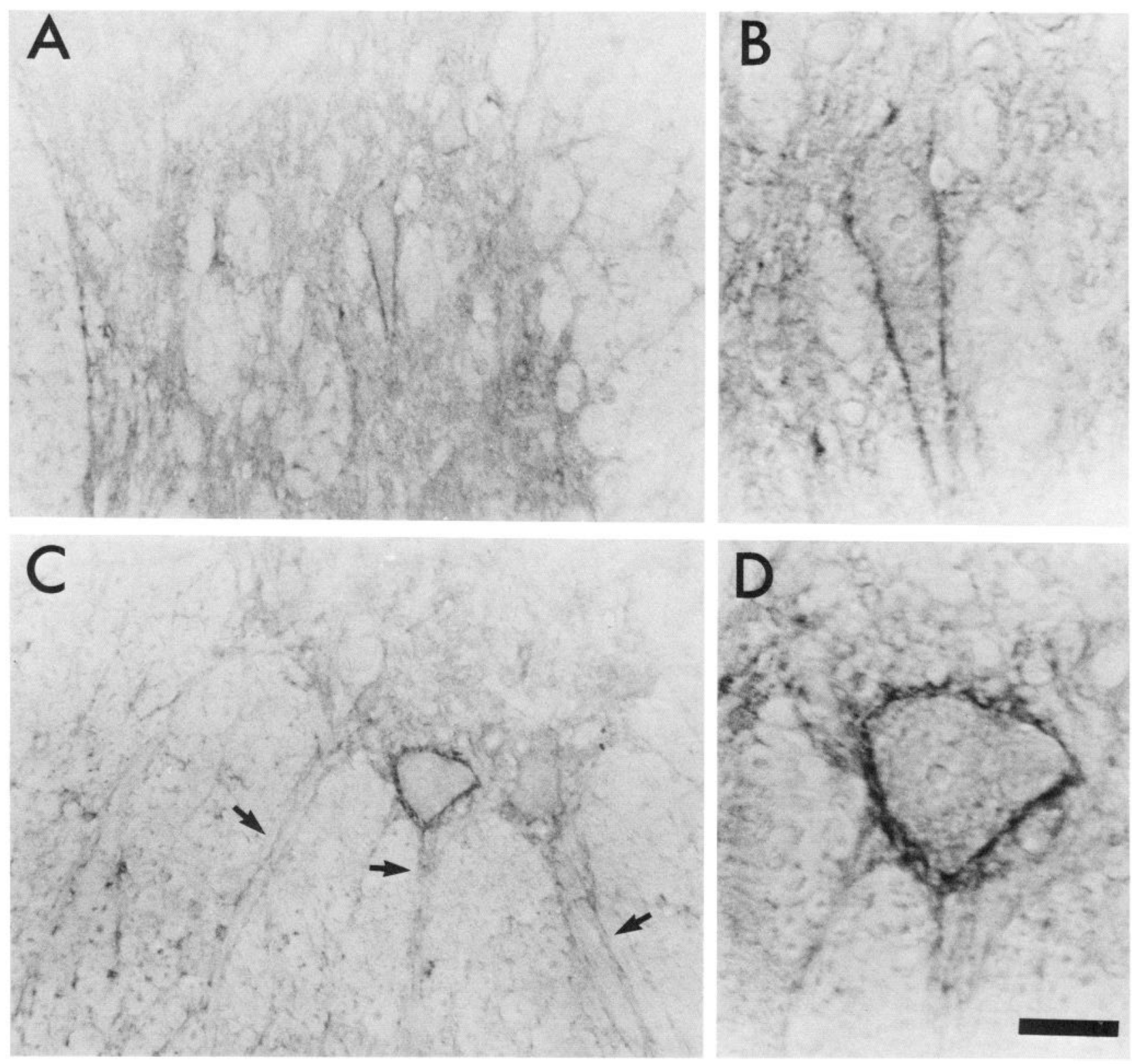

Figure 12. Tor 23 peroxidase localization in thoracic spinal cord. Photomicrographs on the right are high-power micrographs taken from the center of the field shown on the left. $A, B$, In lamina $\mathrm{V}$ of the intermediate gray, Tor 23 precisely outlines a vertically elongated perikaryon. $C, D$, In the ventral horn, lamina IX, immunoreactivity is present on a large alpha-motor neuron. Note stained processes extending into the white matter ( $C$, arrows). Tor 23 stains these 2 neuronal types similarly: antibody binding is present all along the apparent perimeter of the soma and is absent from the cytoplasm. Scale bar, $50 \mu \mathrm{m}(A, C) ; 20 \mu \mathrm{m}(B, D)$.

the medial vestibular nucleus and spinal vestibular nucleus, Tor 23 -positive neurons were only rarely found ( $1-5$ neurons stained per tissue section).

Cranial motor nuclei. Tor 23 localized to motor neurons, both in specific cranial motor nuclei and in the spinal cord. Not all motor neurons were positive for Tor 23 binding, however. Neurons of the oculomotor nucleus (3) on no occasion displayed immunoreactivity. The hypoglossal nucleus (12) and abducens nucleus (6), for the most part, were not immunoreactive; on occasion, a few dimly labeled somata were observed. The dorsal motor nucleus of vagus (10) contained Tor 23-specific stain similar to that observed in the piriform cortex (Fig. 7A). Unlike the piriform cortex, however, immunoreactivity was not detected along the perimeters of neurons. Tor 23 did localize to a significant number of neurons in the motor trigeminal nucleus (5) and in the facial motor nucleus (7). In motor 5, approximately $30-45 \%$ of the neurons displayed Tor 23 staining along their perimeters. Rare, positive neurons were observed in the spinal trigeminal nucleus. Immunopositive neurons of the facial motor nucleus were less frequent than those in motor 5 and comprised $15-20 \%$ of total neurons. Immunoreactivity was also present on a small cluster of intensely AChE-positive neurons extending throughout the caudal medulla, which corresponded to nucleus ambiguus.

\section{Spinal cord}

In the spinal cord, Tor 23 localized to a small, infrequent cell type in the intermediate gray (Fig. 12, $A, B$ ) and to all ventral 
horn motor neurons (Fig. 12, C, D; Kushner, 1984). If one considers its great length, the spinal cord must contain the largest total number of Tor 23-positive neurons in the nervous system. Figure $12(C, D)$ presents a photomicrograph of a stained alphamotor neuron. It measured $50 \mu \mathrm{m}$ in diameter and was prominently positive for Tor 23 binding, with immunoreactivity distributed along the entire apparent neuronal plasma membrane. Stained processes radiated out into the adjacent white matter (Fig. 12C, arrows). Ventral horn motor neurons within a particular field often displayed different intensities of stain, i.e., some neurons were labeled more heavily than others. The second category of Tor 23-positive somata in the spinal cord was variously located in laminae III-V. These neurons were very few in number relative to the frequency of labeled neurons in lamina IX (the motor neurons). Most often, stained somata of the intermediate gray were small (averaging $10 \times 18 \mu \mathrm{m}$ ), but occasionally they were large (Fig. $12 B$ ). They were most frequently fusiform in shape and oriented dorsoventrally (Fig. 12, $A, B$ ), but were sometimes spherical, perhaps representing fusiformshaped cells oriented rostrocaudally.

\section{Summary}

The photomicrographic data presented are highlights of the areas with Tor 23-immunoreactive somata. A complete list of the anatomical structures of the rat brain and spinal cord containing Tor 23-positive neurons is presented in Table 1 . This list is an inclusive summary of the mapping study and indicates the relative densities of immunoreactive somata in each area.

\section{Discussion}

The present study describes the location of neurons that are labeled with Tor 23, a monoclonal antibody that defines a rare neuronal surface antigen. Tor 23 outlines a highly discrete set of neurons in the rat CNS. In general terms, in the forebrain, Tor 23-positive neurons predominate as a rare cell type of the inner cortical laminae. In the midbrain, few cells stain. In the hindbrain, rare, labeled neurons are dispersed among several brain stem nuclei. The exceptions to these observations, areas that contain exclusively, or almost exclusively, Tor 23-immunopositive neurons, are the spinal cord ventral horn, the deep cerebellar nuclei, some cerebellar-related nuclei of the brain stem, selected brain stem auditory nuclei, the supraoptic and paraventricular nuclei of the hypothalamus, and the CA2 pyramidal neurons of the hippocampus.

The neurons that bind Tor 23 are related biochemically by virtue of that shared epitope alone. A shared epitope, however, does not necessarily imply the same antigenic molecule. All of the evidence collected to date indicate that Tor 23 recognizes only one or very few molecules. In Torpedo electroplax terminals, we have established that Tor 23 identifies only 2 antigenic polypeptides, one of $180,000 \mathrm{Da}$, the other of 68,000 Da (Kushner et al., 1987b). Furthermore, these polypeptides share the unusual property of being both integral and peripherally associated membrane components and are thereby likely to be functionally related (Kushner et al., 1987b). Because of the low amount of Tor 23 binding in the rat brain, the biochemical analysis of the mammalian antigenic species might best be approached by cloning and sequencing the gene product(s) identified by Tor 23. Preliminary evidence indicates a single antigenic polypeptide of 175,000 Da in the rat brain (Kushner and Stephenson, 1983; and unpublished observations).
Surface antigenic differences among neurons promise new dimensions in the analysis of the nervous system, from structure and function to development and dysfunction. Recent findings suggest that polypeptides are the basis for antigenic surface differences between groups of neurons in the mature brain (e.g., Wood et al., 1982; Flaster et al., 1983; Levitt et al., 1986; Arimatsu et al., 1987; Kushner et al., 1987b; Patel et al., 1987). One issue that is important to explore and certainly not to lose in the excitement of pinning down the molecular basis for surface antigenic differences is the determination of whether a cell surface property that defines a neuron defines that cell in a meaningful way within the nervous system. A unique, molecular property distributed along the neuronal membrane of positive neurons would literally color code a neuron within its environment. An analogy to this work is that on the immune system, where the compilation of cells into antigenic surface groups contributed profoundly to the functional analysis of the immune system as a collection of separate, but related and interacting, cell types. In the nervous system, do surface markers subdivide neurons into coherent, functional groupings?

In addressing the question of whether neurons identified by Tor 23 are functionally related, we see 3 alternative hypotheses. First, the expression of this neuronal surface antigen by a subset of neurons strictly describes a functional group of CNS neurons. Second, surface antigens expressed by neurons in no way reflect the functional constellation of neurons thus identified. Third, neuronal surface subsets reflect functional groupings, but in an imprecise manner. On reviewing our data in the light of these possibilities, it is apparent that Tor 23 demarks predominantly motor and motor-related structures, specifically, the ventral horn motor lamina, the orofacial motor nuclei 5 and 7, the ambiguus nucleus, the deep cerebellar nuclei, the pontine reticulotegmental nucleus, the lateral reticular nucleus, the gigantocellular reticular nucleus, the red nucleus, and neurons within the motor and somatosensory cortices. Tor 23 is one of a large collection of monoclonal antibodies generated to purified nerve terminals, the result of a project whose goal was the identification and characterization of previously unknown cell surface components of motor neurons (Kushner, 1984). At the time of that project, we anticipated that we would discover antigenic propertics unique to motor neurons or, if not unique, at least shared with few other cell types. Therefore, an association of Tor 23 binding with motor systems seems reasonable. Supportive evidence of the association of Tor 23 with motor systems is of several sorts: (1) Tor 23 binds a highly conserved determinant of motor neurons that is present in rays (Kushner et al., 1987b), rats (Kushner, 1984; Stephenson et al., 1987; and this study), and humans (Kushner et al., 1987a; Bjornskov et al., 1988); (2) in the ray, Tor 23 binds an epitope unique to the presynaptic or nerve form of AChE (Kushner et al., 1987b); and (3) work in progress in the rat suggests that there is a strong overlap with cholinergic neurons (Stephenson and Kushner, 1986; unpublished observations).

The overlap of Tor 23 with motor system structures is not complete: all motor systems are not Tor 23-positive, and some systems other than motor are positive. The cranial motor nuclei 3,6 , and 12 , as well as cells of the striatal extrapyramidal motor system, are negative. Other Tor 23-positive structures are not functionally motor systems. The outstanding example is the auditory system. Primary auditory structures that are strongly Tor 23-positive include the ventral cochlear nuclei, the superior olivary complex, the trapezoid body nuclei, the ventral peri- 


\section{Table 1. Distribution of Tor 23-immunoreactive somata in the rat} nervous system

Immunoreactive

CNS region somata

\section{Forebrain}

Cortex

Frontoparietal cortex, motor

Frontoparietal cortex, somatosensory

Auditory cortex

Striate cortex

Cingulate cortex (anterior and posterior)

Insular cortex

Piriform cortex

Hippocampal formation

Hippocampus proper

Dentate gyrus

CA1

$\mathrm{CA} 2$

$\mathrm{CA} 3$

CA4

Subiculum (pre- and para-)

Entorhinal cortex

Septal area

Lateral septal $\mathbf{n}$.

Medial septal $\mathbf{n}$.

N. of the diagonal band

Vertical limb

Horizontal limb

N. accumbens

Bed n. stria terminalis

Basal forebrain

Caudate putamen

Globus pallidus

Substantia innominata

Nucleus basalis

Entopeduncular $n$.

Ventral pallidum

Islands of Calleja

Prcoptic area, medial and lateral

Claustrum

Endopiriform $\mathrm{n}$.

Amygdala

Thalamus

Anterior thalamus (dorsal, ventral, medial)

Ventral thalamus (lateral, medial, post.)

Lateral thalamus (dorsal, posterior)

Posterior thalamic nuclear group

Central medial thalamic $n$.

Mediodorsal thalamic $n$.

Paraventricular thalamic $n$.

Reticular thalamic $n$.

Rhomboid thalamic $\mathbf{n}$.

Subthalamic n.

Zona incerta

Hypothalamus

Lateral hypothalamic area

Medial hypothalamus

Anterior hypothalamus

Posterior hypothalamus

Dorsal hypothalamic area
Table 1. Continued

Immuno-

reactive

CNS region

somata

Arcuate $\mathrm{n}$.

Paraventricular $\mathrm{n}$.

Suprachiasmatic $\mathrm{n}$.

Supraoptic n.

Mammilary $\mathbf{n}$.

Epithalamus

IIabenula, medial

Habenula, lateral

Interpeduncular $\mathbf{n}$.

Olfactory bulb

Main olfactory bulb

Glomerular layer

External plexiform layer

Mitrial cell layer

Internal plexiform layer

Internal granular layer

Ependyma and subependymal layer

Anterior olfactory nuclei

Olfactory tubercle

$-$

$+++$

$-$

$++$

$-1+$

$-$

$-$

$-1+$

Midbrain and hindbrain

Substantia nigra

Compact part

Reticular part

Lateral part

Locus coeruleus

Central (A6 group)

Posterior (A4 group)

Rostroventral (A7 group)

Raphe nuclei

Caudal linear $n$.

Dorsal raphe

Median raphe

Raphe pontis

Raphe magnus

Raphe obscurus

Raphe pallidus

Precerebellar nuclei

Pontine nuclei

Reticulotegmental $\mathrm{n}$.

Inferior olivary $\mathbf{n}$.

Lateral reticular $\mathrm{n}$. of the medulla

$++$

$-1+$

$+++$

Red núcleus

Magnocellular part

$++$

Parvocellulấr part

$++$

Cerebellum

Central cerebellar nuclei

Medial cerebellar n. (fastígial) +++

Interposed cerebellar $\mathrm{n}$. (interpositus) $\quad+++$

Lateral cerebellar $\mathrm{n}$. (dentate) $\quad+++$

Cerebellar cortex

Molecular layer

Purkinje cell layer

Granule cell layer

Reticular formation, central-gray, and related tegmental nuclei

Mesencephalic reticular nuclei

Cunciform $\mathbf{n}$.

$-1+$

Deep mesencephalic $\mathrm{n}$. 
Table 1. Continued

\begin{tabular}{|c|c|}
\hline CNS region & $\begin{array}{l}\text { Immuno- } \\
\text { reactive } \\
\text { somata }\end{array}$ \\
\hline Central gray & - \\
\hline Dorsal tegmental $\mathrm{n}$. & - \\
\hline Laterodorsal tegmental $\mathrm{n}$. & $-1+$ \\
\hline \multicolumn{2}{|l|}{ Pontine reticular nuclei } \\
\hline Pontine reticular $\mathbf{n}$ & + \\
\hline Ventral tegmental $n$ & - \\
\hline Pedunculopontine tegmental $\mathrm{n}$. & ++ \\
\hline Suprageniculate $n$. of pons & - \\
\hline \multicolumn{2}{|l|}{ Medullary reticular nuclei } \\
\hline Medullary reticular n., ventral & ++ \\
\hline Medullary reticular n., dorsal & + \\
\hline Paramedian reticular $\mathrm{n}$. & $-1+$ \\
\hline Parvocellular reticular $\mathrm{n}$. & + \\
\hline Gigantocellular reticular $\mathrm{n}$. & ++ \\
\hline Paragigantocellular ret. n. & + \\
\hline \multicolumn{2}{|l|}{ Vestibular nucleus complex } \\
\hline Superior vestibular $\mathrm{n}$ & ++ \\
\hline Lateral vestibular $n$. & ++ \\
\hline Medial vestibular $n$. & + \\
\hline Spinal vestibular $\mathbf{n}$. & + \\
\hline Prepositus hypoglossal $\mathrm{n}$. & $-/+$ \\
\hline \multicolumn{2}{|l|}{ Structures associated with auditory system } \\
\hline \multicolumn{2}{|l|}{ Cochlear nuclei } \\
\hline Anterior ventral cochlear $n$. & +++ \\
\hline Postcrior ventral cochlear $\mathrm{n}$ & +++ \\
\hline Granule cell layer cochlear $\mathbf{n}$. & - \\
\hline Dorsal cochlear n. & - \\
\hline \multicolumn{2}{|l|}{ Superior olivary complex } \\
\hline Medial superior olive & ++ \\
\hline Superior pariolivary $\mathrm{n}$. & ++ \\
\hline Lateral superior olive & +++ \\
\hline Trapezoid body nuclei, medial and lateral & +++ \\
\hline Ventral periolivary $n$ & ++ \\
\hline \multicolumn{2}{|l|}{ Nuclei of lateral lemniscus } \\
\hline Ventral lateral lemniscus & ++ \\
\hline Dorsal lateral lemniscus & + \\
\hline \multicolumn{2}{|l|}{ Inferior colliculus (IC) } \\
\hline Central IC & $-1+$ \\
\hline Pericentral IC & - \\
\hline External IC & + \\
\hline \multicolumn{2}{|l|}{ Medial geniculate body } \\
\hline Principal division, ventral & - \\
\hline Principal division, dorsal & - \\
\hline Medial division & - \\
\hline \multicolumn{2}{|l|}{ Structures associated with visual system } \\
\hline \multicolumn{2}{|l|}{ Superior colliculus } \\
\hline Superficial layer & - \\
\hline Optic layer & $-1+$ \\
\hline Intermediate layers & - \\
\hline Deep layers & - \\
\hline Edinger-Westphal $\mathrm{n}$. & - \\
\hline Oculomotor n. (3) & - \\
\hline Trochlear n. (4) & - \\
\hline Lateral geniculate $n$. & - \\
\hline Parabigeminal $\mathrm{n}$. & $-/+$ \\
\hline Rhabdoid n. & - \\
\hline
\end{tabular}

Table 1. Continued

\begin{tabular}{|c|c|}
\hline CNS region & $\begin{array}{l}\text { Immuno- } \\
\text { reactive } \\
\text { somata }\end{array}$ \\
\hline \multicolumn{2}{|l|}{ Sensory trigeminal nuclei } \\
\hline Mesencephalic trigeminal n. & - \\
\hline Principal sensory n. & $-1+$ \\
\hline \multicolumn{2}{|l|}{ N. of the spinal tract } \\
\hline Oral subnucleus & + \\
\hline Interpolar subnucleus & + \\
\hline Caudal subnucleus & + \\
\hline \multicolumn{2}{|l|}{ Brain stem nuclei, autonomic } \\
\hline N. of the solitary tract & $-1+$ \\
\hline Dorsal motor $n$. of vagus ( 10 ) & - \\
\hline Ambiguus $\mathrm{n}$. & ++ \\
\hline \multicolumn{2}{|l|}{ Parabrachial $\mathrm{n}$. } \\
\hline Ventral n. & - \\
\hline Dorsal n. & - \\
\hline Kölīiker Fuse n. & - \\
\hline \multicolumn{2}{|l|}{ Orofacial motor nuclei } \\
\hline Motor trigeminal n. (masticator) (5) & ++ \\
\hline Facial n. (7) & + \\
\hline Abducens n. (6) & $-1+$ \\
\hline Hypoglossal n. (12) & $-1+$ \\
\hline \multicolumn{2}{|l|}{ Spinal cord } \\
\hline Lamina I & - \\
\hline Lamina II & $-1+$ \\
\hline Lamina III & + \\
\hline Lamina IV & + \\
\hline Lamina V & + \\
\hline Lamina VI & $-1+$ \\
\hline Lamina VII & $-1+$ \\
\hline Lamina VIII & ++ \\
\hline Lamina IX & $t+t$ \\
\hline Intermediolateral cell column & $-1+$ \\
\hline
\end{tabular}

The distribution of Tor 23-immunoreactive neurons in the rat CNS. Anatomical structures are subdivided according to Paxinos (1985). Presence of immunoreactive somata in a particular region: + , rare cells $(1-10 \%) ;++$, many cells $(20-60 \%)$; $1 / 1$, most, if not all, cells $(75-100 \%)$; 1, , a region where on few occasions rare cells are observed; -, no Tor 23-positive cells are observed. n., Nucleus.

olivary nucleus, and the ventral nucleus of the lateral lemniscus. The strong overlap of many auditory structures is emphasized by the lack of overlap with structures associated with the visual system. Curiously, the vestibular nuclei, the other eighth-nerve afferent system, are also strongly positive. The other major category of Tor 23 staining that is not explained by a relationship to motor function is Tor 23 cortical cells and the immunopositive neurons of the hippocampus. In the isocortex, Tor 23 outlines rare polydendritic cells of laminae II-IV, while in the hippocampus, Tor 23 outlines rare pyramidal cells of CA1 and $\mathrm{CA} 3$ and all of the pyramidal cells of the CA2 region.

Therefore, Tor 23 has a strong, but not exclusive, association with motor neurons. One must conclude that of the 3 possible hypotheses, the third, or last, must be correct: Tor 23 identifies a functional grouping imprecisely. A precedent for this finding is the description of the LAMP antibody and its associations with most limbic and limbic-related structures (Levitt, 1984). Some of the imprecision of functional grouping may be random; other imprecisions may reflect a phylogenetic or ontogenetic history. In the evolution of the nervous system, a structure might 
be a derivative of the motor system that has evolved to a more specialized, nonmotor function. Additionally, the specific immunogen for Tor 23 was from the Torpedo electric organ, whose embryological origin is the branchial arch. It is thus not precisely equivalent to spinal cord motor neurons; neurons and structures so defined may be specifically related to a branchial arch origin. Because Tor 23 has been found to cross-react with every vertebrate species tested except for chick: ray, frog, human (Kushner, 1984; Kushner et al., 1987a, b; Bjornskov et al., 1988); several teleost species, cat (unpublished observations), it demonstrates the presence of a highly conserved epitope and thus may help resolve the phylogenetic origins of the structures it recognizes.

Tor 23 may also be useful for ontogenetic studies. The analysis of neuronal lineages and their potential functional relatedness is a prerequisite to an understanding of the organization in the nervous system. Avenues to this study have employed celltracing experiments on the basis of morphology (e.g., Sulston and Horvitz, 1977; Bate et al., 1981; Goodman et al., 1981; Sulston et al., 1983), tracing with dyes (e.g., Weisblat et al., 1980; Jacobson, 1983; Moody and Jacobson, 1983; Kimmel and Warga, 1986; Metcalfe et al., 1986), tracing with dyes or using morphology in combination with transmitter identification (Taghert and Goodman, 1984; Stuart et al., 1987), and, more recently, tracing with a marker introduced with a viral vector (Turner and Cepko, 1987). As in the immune system, the analysis of cell lineage in the nervous system may eventually employ cell surface antigenic markers, although at the present this approach has been employed only to a limited extent (Stewart et al., 1987). Hopefully, the establishment of surface markers of sets and subsets of neurons will provide a new wave of probes useful to investigate the lineage relationship of functional neuronal groups. Work in progress indicates that the epitope defined by Tor 23 is present early, relative to the development of other transmitter-related intracellular markers (P. D. Kushner and E. A. Neale, unpublished observations), and thus strengthens the idea that Tor 23 may help define the ontogenetic, as well as the phylogenetic, origins of the structures it identifies.

One of the intriguing issues to be addressed is the differential presence of Tor 23 within brain nuclei. Do the cranial nerve nuclei that have Tor 23-positive neurons share an ontogenetic or phylogenctic origin? Also, do other Tor 23-positive structures have a shared origin with motor neurons? The Tor 23-positive systems that are potentially most reasonably related to a motor or branchial arch system are the auditory and the vestibular systems, since they are both afferents of a cranial nerve that may have an evolutionary history within motor structures. The forebrain neurons will be more difficult to analyze, owing to the obvious evolutionary complexity of the forebrain generally. According to a recently summarized theory of cortical organization, memory and perception may involve a complex cross-referencing system (Altman, 1987). Concomitantly, the "sporadic" distribution of Tor 23 in the cortex in areas other than motor and somatosensory cortices may reflect its aspect in other representations of sensory/motor maps. Likewise, immunopositive neurons of hippocampal areas may be those involved in upper-level motor function, i.e., motivational or decision-making, or in an cmotional state with immediate expression in motor function. In the hippocampus proper, Tor 23 identifies very special cells: all of the pyramidal cells of the CA2 layer, rare pyramidal neurons of $\mathrm{CA} 1$ and $\mathrm{CA} 3$ that are often ectopic, and cells lying just deep to the alveus. The CA2 layer of the hippocampus is known for its special electrical properties, in that it is a site of burst origination (Wong and Traub, 1983; Knowles et al., 1987), although this layer cannot be unequivocably distinguished in electrophysiological preparations. Therefore, even though the more esoteric issues concerning Tor 23-positive neurons may be difficult to resolve, in practical terms Tor 23 may be useful as a vital dye to allow the in vitro identification of CA2 cells and other, related pyramidal cells.

Finally, neuronal cell surface molecules must play an obvious and vital role in development. Cell-to-cell adhesion and cell attraction are, at one level, mediated through cell surface molecules. While some important surface molecules subserving developmental events are the same for all neurons and vary in the site and the timing of their expression (Edelman, 1984; Rutishauser, 1984), others may appear only on specific sets and subsets of neurons and serve to identify precisely particular neurons within a microenvironment. We have begun our analysis of the surface markers in the mature brain because, compared to the complexity of the developing brain, with its temporal differences in the dynamic events of neuronogenesis, cell migration, axonogenesis, and synaptogenesis, the mature brain is a simplification. At maturity, surface molecules that define sets and subsets can be identified and the neurons that are positive coidentified with the established body of information on the neuronal types of the brain. It seems obvious that the molecule defined by Tor 23 may play a profound role in development. In fact, it is harder to understand why the mature nervous system would use a system of surface markers than why the developing brain would. We may consider 2 things: (1) evidence is accumulating that the brain is more plastic than was previously considered (Merzenich, 1987) and thus may need permanent surface markers; and (2) in times of stress and dysfunction, surface molecules may be the guideposts for recovery, which, once lost, lead to certain dysfunction.

\section{References}

Allen, W. K., and R. Akeson (1985) Identification of a cell surface glyocoprotein family of olfactory receptor neurons with a monoclonal antibody. J. Neurosci. 5: 284-296.

Altman, J. (1987) A quiet revolution in thinking. Nature 328: 572573.

Amaral, D. G. (1978) A Golgi study of cell types in the hilar region of the hippocampus in the rat. J. Comp. Neurol. 182: 851-914.

Andrezik, J. A., and A. J. Beitz (1985) Reticular formation, central gray and related tegmental nuclei. In The Rat Nervous System, vol. 2, G. Paxinos, ed., pp. 1-28, Academic, Orlando, FL.

Arimatsu, Y., J. R. Naegele, and C. J. Barnstable (1987) Molecular markers of neuronal subpopulations in layers 4,5 , and 6 of cat primary visual cortex. J. Neurosci. 7: 1250-1263.

Armstrong, D. M., C. B. Saper, A. I. Levey, B. H. Wainer, and R. D. Terry (1983) Distribution of cholinergic neurons in rat brain: Demonstrated by the immunocytochemical localization of choline acetyltransferase. J. Comp. Neurol. 216: 53-68.

Barber, R. P., P. E. Phelps, C. R. Houser, G. D. Crawford, P. M. Salvaterra, and J. E. Vaughn (1984) The morphology and distribution of neurons containing choline acetyltransferase in the adult rat spinal cord: An immunocytochemical study. J. Comp. Neurol. 229: 329-346.

Barnstable, C. J., K. Akagawa, R. Hofstein, and J. P. Horn (1983) Monoclonal antibodies that label discrete cell types in the mammalian nervous system. Cold Spring Harbor Symp. Quant. Biol. 48: 863876.

Bate, M., C. S. Goodman, and N. C. Spitzer (1981) Embryonic development of identified neurons: Segment-specific differences in the $\mathrm{H}$ cell homologues. J. Neurosci. 1: 103-106.

Bjornskov, E., D. T. Stephenson, E. Denys, and P. D. Kushner (1988) Monoclonal antibodies made to Torpedo nerve terminals identify 
cytochemical components of the human peripheral nervous system. Muscle Nerve 11: 10-20.

Brawer, J. R., D. K. Morest, and E. C. Kane (1974) The neuronal architecture of the cochlear nucleus of the cat. J. Comp. Neurol. 155: 251-300.

Buckley, K. M., E. S. Schweitzer, G. P. Miljanich, L. Clift-O'Grady, P. Kushner, L. F. Reichardt, and R. Kelly (1983) A synaptic vesicle antigen is restricted to the junctional region of the presynaptic plasma membrane. Proc. Natl. Acad. Sci. USA 80: 7342-7346.

Cohen, J., and S. Y. Selvendran (1981) A neuronal cell-surface antigen is found in the CNS but not in peripheral neurones. Nature 291:421423.

Delpech, B., N. Girard, and B. Delpech (1982) Localization of hyaluronectin in the nervous system. Brain Res. 245: 251-257.

Donoghuc, J. P., and S. P. Wisc (1982) The motor cortex of the rat: Cytoarchitecture and microstimulation mapping. J. Comp. Neurol. 212: 76-88.

Edelman, G. M. (1984) Modulation of cell adhesion during induction of histogenesis and perinatal development of the nervous system. Annu. Rev. Neurosci. 7: 339-377.

Flaster, M., C. Shley, and B. Zipser (1983) Generating monoclonal antibodies against excised gel bands correlated to immunocytochemical and biochemical data. Brain Res. 277: 196-199.

Games, K. D., and J. A. Winer (1988) Projections of layer V in rat auditory cortex: Contrasting morphology and sublaminar distribution of neurons projecting to the inferior colliculus and contralateral cortex. Hearing Res. (in press).

Garson, J. A., P. C. L. Beverley, H. B. Coakham, and E. I. Harper (1982) Monoclonal antibodies against human $\mathrm{T}$ lymphocytes label Purkinje neurones of many species. Nature 298: 375-377.

Goodman, C. S., M. Bate, and N. C. Spitzer (1981) Embryonic development of identified neurons: Origin and transformation of the $\mathrm{H}$ cell. J. Neurosci. 1: 94-102.

Harrison, J. M., and M. L. Feldman (1970) Anatomical aspects of the cochlear nucleus and superior olivary complex. In Contributions to Sensory Physiology, W. D. Neff, ed., pp. 95-142, Academic, New York.

Hogg, N., M. Flaster, and B. Zipser (1983) Cross reactivities of monoclonal antibodies between select leech neuronal and epithelial tissue. J. Neurosci. Res. 9: 445-457.

Hockfield, S. J., and R. D. McKay (1983) A surface antigen expressed by a subset of neurons in the vertebrate CNS. Proc. Natl. Acad. Sci. USA 80: $5758-5761$.

Hockfield, S., R. D. McKay, S. H. C. Hendry, and E. G. Jones (1983) A surface antigen that identifies ocular dominance columns in the visual cortex and laminar features of the lateral geniculate nucleus. Cold Spring Harbor Symp. Quant. Biol. 48: 877-890.

Houser, C. R., G. D. Crawford, R. P. Barber, P. M. Salvaterra, and J. E. Vaughn (1983) Organization and morphological characteristics of cholinergic neurons: An immunocytochemical study with a monoclonal antibody to choline acetyltransferase. Brain Res. 266: 97-119.

Jacobson, M. (1983) Clonal organization of the central nervous system of the frog. III. Clones stemming from individual blastomeres of the 128-, 256-, and 512-cell stages. J. Neurosci. 3: 1019-1038.

Kimmel, C. B., and R. M. Warga (1986) Tissue-specific cell lineages originate in the gastrula of the zebrafish. Science 231: 365-368.

Knowles, W. D., R. D. Traub, and B. W. Strowbridge (1987) The initiation and spread of epileptiform bursts in the in vitro hippocampal slice. Neuroscience 21: 441-455.

König, J. F. R., and R. A. Klippel (1974) The Rat Brain: A Stereotaxic Atlas of the Forebrain and Lower Parts of the Brain Stem, Krieger, New York.

Kushner, P. D. (1984) A library of monoclonal antibodies to Torpedo cholinergic synaptosomes. J. Neurochem. 43: 775-786.

Kushner, P. D., and D. T. Stephenson (1983) A Torpedo monoclonal antibody that defines a subset of mammalian neurons. Soc. Neurosci. Abstr. 9: 758.

Kushner, P. D., G. Cole, and H. Sternberg (1987a) A human teratocarcinoma which expresses a rare neuronal cell surface antigen. Mol. Brain Res. 2: 271-275.

Kushner, P. D., D. T. Stephenson, H. Sternberg, and R. Weber (1987b) Monoclonal antibody Tor 23 recognizes a determinant of presynaptic acetylcholinesterase. J. Neurochem. 48: 1942-1953.

Levey, A. I., D. M. Armstrong, S. F. Atweh, R. D. Terry, and B. H. Wainer (1983) Monoclonal antibodies to choline acetyltransferase:
Production, specificity, and immunohistochemistry. J. Neurosci. 3: 1-9.

Levitt, P. (1984) A monoclonal antibody to limbic system neurons. Science 223: 299-301.

Levitt, P., E. Pawlak-Byczkowska, H. L. Horton, and V. Cooper (1986) Assembly of functional systems in the brain: Molecular and anatomical studies of the limbic system. In The Neurobiology of Down Syndrome, C. J. Epstein, ed., pp. 195-209, Raven, New York.

Lorente de Nó, R. (1934) Studies on the structure of the cerebral cortex. II. Continuation of the study of the ammonic system. J. Psychol. Neurol. 46: 113-177.

Matthew, W. D., L. Tsavaler, and L. F. Reichardt (1981) Identification of a synaptic vesicle-specific membrane protein with a wide distribution in neuronal and neurosecretory tissue. J. Cell Biol. 91: 257269.

Merzenich, M. (1987) Dynamic neocortical processes and the origin of higher brain functions. In The Netral and Molecular Basis of Learning, J. P. Changeux and M. Konishi, eds., pp. 337-358, Wiley, New York.

Mesulam, M.-M., E. J. Mufson, B. H. Wainer, and A. I. Levey (1983) Central cholinergic pathways in the rat: An overview based on an alternative nomenclature (Ch1--Ch6). Neuroscience 10: 1185-1201.

Metcalfe, W. K., B. Mendelson, and C. B. Kimmel (1986) Segmental homologies among reticulospinal neurons in the hindbrain of the zebrafish larva. J. Comp. Neurol. 251: 147-159.

Moody, S. A., and M. Jacobson (1983) Compartmental relationships between anuran primary spinal motoneurons and somitic muscle fibers that they first innervate. J. Neurosci. 3: 1670-1682.

Morris, R. J., and P. C. Barber (1983) Fixation of Thy-1 in nervous tissue for immunohistochemistry: A quantitative assessment of the effect of different fixation conditions upon retention of antigenicity and the cross-linking of Thy-1. J. Histochem. Cytochem. 31: 263274.

Navaratnam, V., and P. R. Lewis (1970) Cholinesterase-containing neurones in the spinal cord of the rat. Brain Res. 18: 411-425.

Osen, K. K. (1969) Cytoarchitecture of the cochlear nuclei in the cat. J. Comp. Neurol. 136: 453-484.

Patel, N. H., P. M. Snow, and C. S. Goodman (1987) Characterization and cloning of Fasciclin III: A glycoprotein expressed on a subset of neurons and axon pathways in Drosophila. Cell 48: 975-988.

Paxinos, G. (1985) The Rat Nervous System, vols. 1 and 2, Academic, Orlando, FL.

Paxinos, G., and C. Watson (1982) The Rat Brain in Stereotaxic Coordinates, Academic, New York.

Paxinos, G., and C. Watson (1986) The Rat Brain in Stereotaxic Coordinates, 2nd Ed., Academic, New York.

Peinado, A., E. R. Macagno, and B. Zipser (1987) A group of related surface glycoproteins distinguishes sets and subsets of sensory afferents in the leech nervous system. Brain Res. 410: 335-339.

Peters, A., and E. G. Jones (1984) Cerebral Cortex, vol. 1: Cellular Components of the Cerebral Cortex, Plenum, New York.

Reid, J. M., D. G. Gwym, and B. A. Flumerfelt (1975) A cytoarchitectonic and Golgi study of the red nucleus in the rat. J. Comp. Neurol. 162: 337-362.

Richardson, P. J., J. H. Walker, R. T. Jones, and V. P. Whittaker (1982) Identification of a cholinergic-specific antigen Chol-1 as a ganglioside. J. Neurochem. 38: 1605-1614.

Ruth, R. E., T. J. Collier, and A. Routtenberg (1982) Topography between the entorhinal cortex and the dentate septotemporal axis in rats: I. Medial and intermediate entorhinal projecting cells. J. Comp. Neurol. 209: 69-78.

Rutishauser, U. (1984) Developmental biology of a neural cell adhesion molecule. Nature 310: 549-554.

Rye, D. B., C. B. Saper, H. J. Lee, and B. H. Wainer (1987) Pedunculopontine tegmental nucleus of the rat: Cytoarchitecture, cytochemistry, and some extrapyramidal connections of the mesopontine tegmentum. J. Comp. Neurol. 259: 483-528.

Seress, L. (1978) Pyramid-like basket cells in the granular layer of the dentate gyrus in the rat. J. Anat. 127: 163-168.

Seress, L., and J. Pokorny (1981) Structure of the granular layer of the rat dentate gyrus. A light microscopic and Golgi study. J. Anat. 133: $181-195$.

Sotelo, C., and S. L. Palay (1968) The fine structure of the lateral vestibular nucleus in the rat. I. Neurons and neuroglial cells. J. Cell Biol. 36: 151-179. 
Stephenson, D. T., and P. D. Kushner (1986) A set of limbic and motor neurons in the rat brain is defined by Tor 23. Soc. Neurosci. Abst. 12: 906.

Stephenson, D. T., P. A. St. John, J. L. Barker, and P. D. Kushner (1987) A cell surface epitope which is present on some but not all motor neurons. Soc. Neurosci. Abstr. 13: 1396.

Stewart, R. R., W.-Q. Gao, A. Peinado, B. Zipser, and E. R. Macagno. (1987) Cell death during gangliogenesis in the leech: Bipolar cells appear and then degencrate in all ganglia. J. Ncurosci. 7: 1919-1927.

Stuart, D. K., S. S. Blair, and D. A. Weisblat (1987) Cell lineage, cell death, and the developmental origin of identified serotonin- and dopamine-containing neurons in the leech. J. Neurosci. 7: 1107-1122.

Sulston, J., and H. R. Horvitz (1977) Postembryonic cell lineages of the nematode, Caenorhabditis elegans. Dev. Biol. 56:110-156.

Sulston, J. E., E. Schierenberg, J. G. White, and J. N. Thomson (1983) The embryonic cell lineage of the nematode Caenorhabditis elegans. Dev. Biol. 100: 64-119.

Taghert, P. H., and C. S. Goodman (1984) Cell determination and differentiation of identified serotonin-immunoreactive neurons in the grasshopper embryo. J. Neurosci. 4: 989-1000.

Trisler, D., and F. Collins (1987) Corresponding spatial gradients of TOP molecules in the developing retina and optic tectum. Science 237: 1208-1209.

Turner, D. L., and C. L. Cepko (1987) A common progenitor for neurons and glia persists in rat retina late in development. Nature 328: $131-136$
Valverde, F. (1986) Intrinsic neocortical organization: Some comparative aspects. Neuroscience 18: 1-23.

Vulliamy, T., S. Rattray, and R. Mirsky (1981) Cell-surface antigen distinguishes sensory and autonomic peripheral neurones from central neurones. Nature 291: 418-420.

Webster, W. R. (1985) Auditory system. In The Rat Nervous System, vol. 2, G. Paxinos, ed., pp. 153-185, Academic, Orlando, FL.

Weisblat, D. A., G. Harper, G. S. Stent, and R. T. Sawyer (1980) Embryonic cell lineages in the nervous system of the glossiphoniid leech Helobdella triserialis. Dev. Biol. 76: 58-78.

Wong, R. K. S., and R. D. Traub (1983) Synchronized burst discharge in disinhibited hippocampal slice. I. Initiation in CA2-CA3 region. J. Neurophysiol. 49: 442-458.

Wood, J. N., L. Hudson, T. M. Jessell, and M. Yamamoto (1982) A monoclonal antibody defining antigenic determinants on subpopulations of mammalian neurones and Trypanosoma cruzi parasites. Nature 296: 34-38.

Zilles, K. (1985) The Cortex of the Rat, Springer-Verlag, Berlin.

Zipser, B. (1982) Complete distribution patterns of neurons with characteristic antigens in the leech central nervous system. J. Neurosci 2: 1453-1464.

Zipser, B., and R. McKay (1981) Monoclonal antibodies distinguish identifiable ncurons in the leech. Nature 289: 549-554. 